University of Wollongong

Research Online

$1-1-2017$

\title{
Forward osmosis as a platform for resource recovery from municipal wastewater - a critical assessment of the literature
}

\author{
Ashley Ansari \\ University of Wollongong, ashleyz@uow.edu.au \\ Faisal I. Hai \\ University of Wollongong, faisal@uow.edu.au \\ William E. Price \\ University of Wollongong, wprice@uow.edu.au \\ Jörg E. Drewes \\ Technical University of Munich, jdrewes@mines.edu \\ Long D. Nghiem \\ University of Wollongong, longn@uow.edu.au
}

Follow this and additional works at: https://ro.uow.edu.au/ihmri

Part of the Medicine and Health Sciences Commons

\section{Recommended Citation}

Ansari, Ashley; Hai, Faisal I.; Price, William E.; Drewes, Jörg E.; and Nghiem, Long D., "Forward osmosis as a platform for resource recovery from municipal wastewater - a critical assessment of the literature" (2017). Illawarra Health and Medical Research Institute. 1009.

https://ro.uow.edu.au/ihmri/1009

Research Online is the open access institutional repository for the University of Wollongong. For further information contact the UOW Library: research-pubs@uow.edu.au 


\title{
Forward osmosis as a platform for resource recovery from municipal wastewater - a critical assessment of the literature
}

\begin{abstract}
Forward osmosis (FO) is an emerging membrane separation technology that has the potential to serve as a game changer in wastewater treatment. FO-based processes can simultaneously produce high quality effluent and pre-concentrated wastewater for anaerobic treatment to facilitate the recovery of energy and nutrients. Complex wastewaters can be directly pre-treated by FO and fresh water can be produced when coupled with a draw solute recovery process (i.e. reverse osmosis or membrane distillation). By enriching organic carbon and nutrients for subsequent biogas production, FO extends the resource recovery potential of current wastewater treatment processes. Here, we critically review recent applications of FO for simultaneous treatment and resource recovery from municipal wastewater. Research conducted to date highlights the importance of successfully integrating FO with anaerobic treatment. Emphasis is also placed on the development of novel FO-based hybrid systems utilising alternative energy sources for draw solute recovery. There remain several technical challenges to the practical realisation of FO for resource recovery from wastewater including salinity build-up, membrane fouling, and system scale-up. Strategies to overcome these challenges are critically assessed to establish a research roadmap for further development of FO as a platform for resource recovery from wastewater.
\end{abstract}

\section{Keywords}

platform, resource, recovery, municipal, wastewater, -, critical, assessment, literature, osmosis, forward

\section{Disciplines}

Medicine and Health Sciences

\section{Publication Details}

Ansari, A. J., Hai, F. I., Price, W. E., Drewes, J. E. \& Nghiem, L. D. (2017). Forward osmosis as a platform for resource recovery from municipal wastewater - a critical assessment of the literature. Journal of Membrane Science, 529 195-206. 
1 Forward osmosis as a platform for resource recovery from municipal wastewater - A critical assessment of the literature

Revised Manuscript Submitted to

\section{Journal of Membrane Science}

5 Ashley J. Ansari ${ }^{a}$, Faisal I. Hai ${ }^{a}$, William E. Price ${ }^{b}$, Jörg E. Drewes ${ }^{c}$, Long D. Nghiem *,a

$6 \quad{ }^{a}$ Strategic Water Infrastructure Laboratory, School of Civil, Mining and Environmental 7 Engineering, University of Wollongong, Wollongong, NSW 2522, Australia

${ }^{\mathrm{b}}$ Strategic Water Infrastructure Laboratory, School of Chemistry University of Wollongong, Wollongong, NSW 2522, Australia Coulombwall 3, 85748 Garching, Germany

$15 *$ Corresponding author: Long D. Nghiem, Email longn@uow.edu.au; Tel: +61 242214590 
TABLE OF CONTENTS

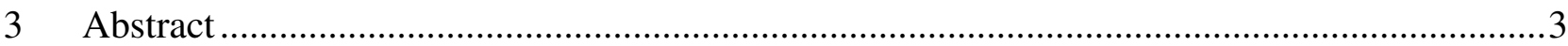

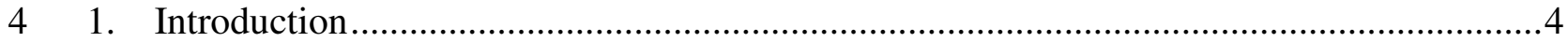

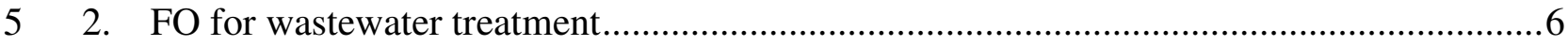

$6 \quad 2.1 \quad$ FO system configurations for wastewater treatment ................................... 6

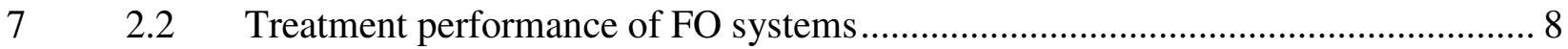

$8 \quad 2.3 \quad$ FO membrane-based hybrid systems for water recovery …................................ 11

$9 \quad 2.3 .1$ Contaminant accumulation in the draw solution ......................................... 12

$10 \quad 2.3 .2$ Energy consideration for FO membrane-based hybrid systems ........................ 13

$11 \quad 2.3 .3$ Other limitations of FO-based hybrid systems ............................................ 15

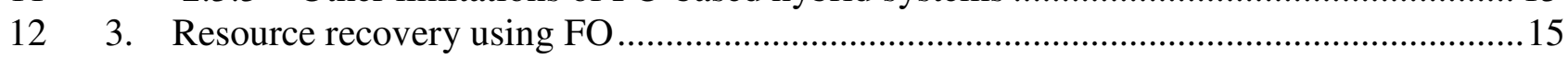

$13 \quad 3.1 \quad$ Integrating FO with anaerobic treatment for biogas production.......................... 17

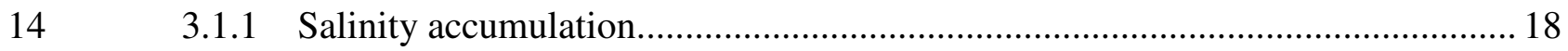

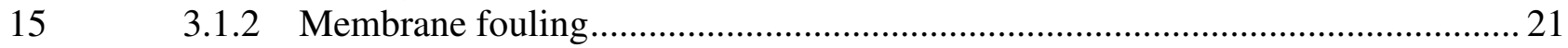

16 3.1.3 Issues arising from the anaerobic treatment of FO pre-concentrated wastewater 22

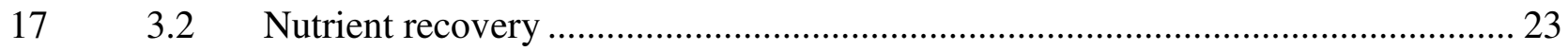

18 4. Integrated FO-based wastewater treatment and resource recovery process ....................25

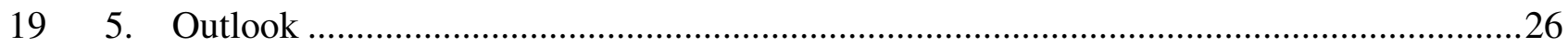

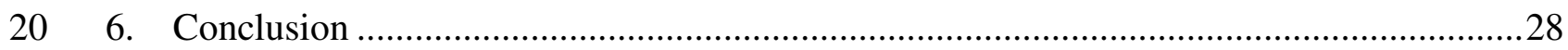

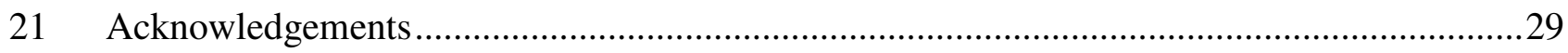

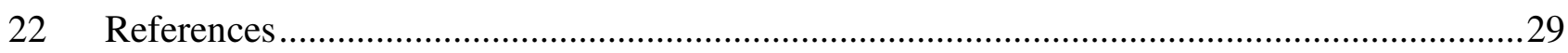




\section{$1 \quad$ Abstract}

2 Forward osmosis (FO) is an emerging membrane separation technology that has the potential 3 to serve as a game changer in wastewater treatment. FO-based processes can simultaneously 4 produce high quality effluent and pre-concentrated wastewater for anaerobic treatment to 5 facilitate the recovery of energy and nutrients. Complex wastewaters can be directly pre6 treated by FO and fresh water can be produced when coupled with a draw solute recovery 7 process (i.e. reverse osmosis or membrane distillation). By enriching organic carbon and 8 nutrients for subsequent biogas production, FO extends the resource recovery potential of 9 current wastewater treatment processes. Here, we critically review recent applications of FO 10 for simultaneous treatment and resource recovery from municipal wastewater. Research 11 conducted to date highlights the importance of successfully integrating FO with anaerobic 12 treatment. Emphasis is also placed on the development of novel FO-based hybrid systems 13 utilising alternative energy sources for draw solute recovery. There remain several technical 14 challenges to the practical realisation of FO for resource recovery from wastewater including 15 salinity build-up, membrane fouling, and system scale-up. Strategies to overcome these 16 challenges are critically assessed to establish a research roadmap for further development of $17 \quad$ FO as a platform for resource recovery from wastewater.

18 Keywords: forward osmosis (FO); wastewater treatment; resource recovery; anaerobic treatment; biogas; phosphorus recovery. 


\section{1. Introduction}

2 The recovery of water, energy, and nutrient resources from municipal wastewater presents a 3 promising solution to a number of prevalent economic, environmental, and social issues.

4 Wastewater reclamation can address both water scarcity and environmental pollution [1, 2].

5 Utilisation of the biogas produced from the organic content of wastewater can offset the

6 energy requirement for treatment [3]. Nutrient recovery from wastewater also deserves

7 special attention due to the increasing stringency of effluent discharge regulations and

8 uncertainties associated with minable phosphorus supply for food security [4-6]. Increasing

9 awareness of the potential resource value of municipal wastewater has prompted significant

10 research efforts to synergise emerging wastewater treatment processes and resource recovery 11 techniques $[3,7,8]$.

12 Activated sludge treatment is an established biological process that focusses primarily on 13 purifying wastewater of organic matter, pathogens, and nutrients, but does not effectively 14 facilitate energy and nutrient recovery. Activated sludge treatment is energy intensive due to 15 the high electricity demand for aeration and also produces excessive amounts of sludge residuals [9]. During activated sludge treatment, the carbon (i.e. chemical energy) and nitrogen (i.e. nutrient) contents of wastewater are converted to biomass, carbon dioxide, and nitrogen gas. In other words, much of the energy and nutrient contents of wastewater are dissipated at the expense of significant energy input. As an alternative, anaerobic treatment converts organic substances into methane rich biogas in the absence of oxygen and transforms phosphorus to a more chemically available state for subsequent recovery [10]. Transitioning from aerobic towards anaerobic based treatment processes has significant potential to lower the energy consumption of wastewater operations (i.e. by avoiding aeration), as well as achieve energy-neutral wastewater treatment (i.e. through biogas production) [11-17].

The opportunity for wastewater treatment plants to provide a renewable source of useful heat and electricity through biogas conversion is immense $[18,19]$. In fact, the chemical energy content in municipal wastewater exceeds the electricity requirement of operating an activated sludge plant by at least nine times [20]. Despite this significant embedded energy content, there are a number of major challenges that currently restrict the feasibility of directly anaerobically digesting raw wastewater for energy recovery. The concentration of organic matter in wastewater is typically low. Therefore, a sufficient organic loading rate cannot be maintained in the anaerobic digester, resulting in a low biogas yield and inadequate removal 
1 of organic pollutants from wastewater. In addition, since methane is slightly soluble in water $2(22.7 \mathrm{mg} / \mathrm{L})$, at a low biogas yield, much of the generated methane can be lost via effluent 3 discharge [10]. Several membrane filtration technologies have been integrated with anaerobic 4 treatment to overcome these challenges, aiming to improve the retention of biomass in the reactor and to increase effluent quality. Anaerobic membrane bioreactors (An-MBRs) 6 utilising low pressure membranes such as microfiltration (MF) or ultrafiltration (UF) is a notable approach. Nevertheless, the MF/UF membranes used in conventional An-MBRs cannot retain dissolved organic carbon. Thus, they are not effective for energy recovery and cannot produce a high effluent quality [10].

10 Further development in An-MBR technology has resulted in the novel hybridisation of anaerobic treatment with high retention membrane processes including nanofiltration (NF), membrane distillation (MD), and forward osmosis (FO) [21]. Among these high retention membrane processes, FO stands out as the most promising candidate for integration with anaerobic treatment due to a combination of high separation efficiency and high fouling reversibility [22-25]. The integration of FO with anaerobic treatment has been widely reported in the literature [26-30]. FO is a unique membrane process that utilises the physical phenomenon of osmosis to transport water across a semipermeable membrane. As a major advantage, the FO process itself can operate with minimal external energy input [31]. However, further treatment of the draw solution is required to extract fresh water and can be achieved using pressure driven or thermally driven membrane processes [32]. Lutchmiah, et al. [33] provided a critical assessment of FO applications for water reclamation. They also highlighted the need to develop new membrane materials and optimise draw solute selection as well as key operating conditions to facilitate full-scale implementation of FO for water reclamation applications [33]. In another excellent review, Holloway, et al. [34] systematically summarised and reviewed all relevant works related to osmotic membrane bioreactors for the production of high quality potable water from impaired sources including wastewater. In particular, Xie, et al. [7] identified the untapped potential of FO amongst several other membrane separation processes for recovering nutrients from municipal wastewater. Indeed, there is a consensus that FO has the potential to be an important technology in the future of wastewater treatment $[31,33,35,36]$.

31 Integrating FO with anaerobic treatment is essential for energy and nutrient recovery. The viability of the anaerobic osmotic membrane bioreactor (An-OMBR) has been demonstrated 
1 where the FO membrane is submerged inside the anaerobic bioreactor [26, 28, 29]. An

2 alternative approach uses FO to firstly pre-concentrate raw wastewater to a high strength for

3 subsequent anaerobic treatment. The concept of wastewater pre-concentration is yet to be

4 fully explored, but it holds significant opportunities for resource recovery applications.

5 Preliminary investigations into FO draw solution selection [27, 37] and process efficiency

6 [38-40] have been conducted. However, issues of salinity accumulation, membrane fouling,

7 and anaerobic treatment integration have not been adequately addressed.

8 Here, we critically review recent applications of FO for recovering energy and nutrients from 9 municipal wastewater by integrating with existing resource recovery techniques (i.e., 10 anaerobic digestion and phosphorus precipitation) and other complementary processes (e.g., 11 membrane distillation (MD) and reverse osmosis (RO)) for clean water extraction. The 12 challenges and potential opportunities associated with FO-based treatment processes are 13 evaluated in terms of treatment efficiency and resource recovery potential. The outlook of an 14 integrated FO membrane-based system for simultaneous wastewater treatment and resource 15 recovery is discussed. A research roadmap for further development of FO for resource 16 recovery from wastewater is also provided and discussed.

\section{2. FO for wastewater treatment}

18 Interest in applying FO for wastewater treatment has grown significantly in recent years [32, $1933,35,41-43]$. These potential applications are motivated by several advantages of FO over 20 current wastewater treatment technologies. Given its high fouling reversibility, FO can be 21 directly applied to a complex solution without extensive pre-treatment [44]. A high rejection 22 of dissolved contaminants is another important advantage of FO for wastewater treatment. 23 When FO is combined with a draw solute recovery process, clean water can be produced 24 from the draw solution, furthering water reuse opportunities. These unique features of FO 25 have spurred the development of several system configurations for wastewater treatment and 26 water reclamation.

\subsection{FO system configurations for wastewater treatment}

28 Three major system configurations have been developed for FO wastewater treatment 29 applications and vary depending on the type of solution in contact with the FO membrane 30 (Figure 1). Firstly, the most widely recognised approach is the aerobic osmotic membrane 31 bioreactor (Ae-OMBR) [45-51] (Figure 1A) whereby wastewater is fed into an activated 
1 sludge reactor. Secondly, several research groups have explored the potential of An-OMBRs 2 [26, 28, 29] (Figure 1B) for wastewater treatment and the production of biogas. Both OMBR 3 configurations typically utilise a submerged FO module, as the high solids content of the 4 mixed liquor and digested sludge can cause blockages in other arrangements. The third 5 configuration (Figure 1C) adopts a similar concept to the An-OMBR (Figure 1B). However, 6 in this configuration, wastewater is firstly pre-concentrated by the FO membrane prior to 7 anaerobic digestion $[27,39,52]$. A key benefit of this configuration is that the FO membrane 8 is in contact with concentrated wastewater, which has lower fouling propensity compared 9 with the mixed liquor inside an An-OMBR. Similar to conventional MBRs, the submerged 10 configuration appears most suited for wastewater pre-concentration, to reduce the costs 11 associated with circulating the feed solution through an external membrane module [53].
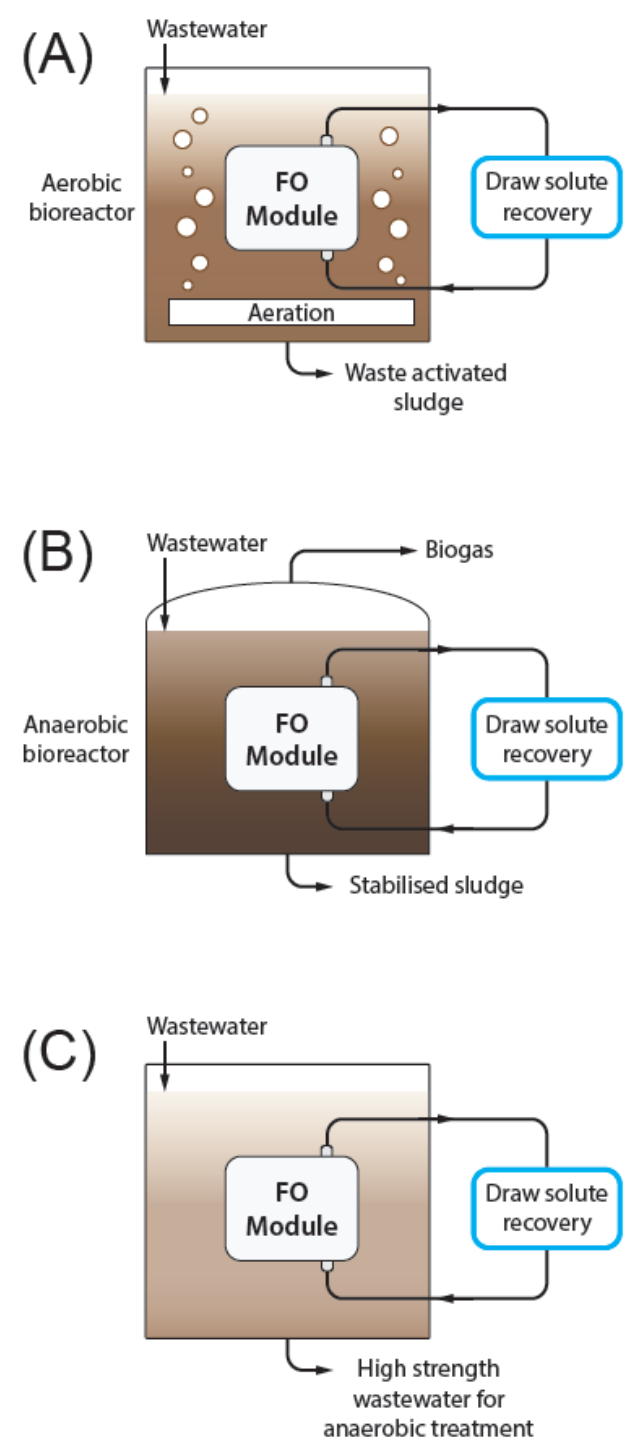
1 Figure 1: Schematic representation of three major FO system configurations for wastewater 2 treatment: (A) Ae-OMBR, (B) An-OMBR, and (C) wastewater pre-concentration intended for subsequent anaerobic digestion.

\section{$4 \quad 2.2 \quad$ Treatment performance of FO systems}

5 The level of treatment provided by each FO system can differ considerably, and can be 6 attributed to the type of applied biological treatment, process conditions, and membrane 7 properties (Table 1). The treatment performance of an FO system is generally indicated by the 8 efficiency to remove organic matter, nitrogen, phosphorus, and trace organic contaminants 9 (TrOCs). 
Table 1: Summary of FO wastewater treatment performance in terms of the removal efficiency of organic matter (i.e. total organic carbon (TOC) and chemical oxygen demand (COD)), phosphorus (i.e. total phosphorus (TP)), and nitrogen (i.e. $\mathrm{NH}_{4}{ }^{+}-\mathrm{N}_{\text {and }}$ total nitrogen (TN)).

\begin{tabular}{|c|c|c|c|c|c|c|c|}
\hline \multirow{3}{*}{$\begin{array}{l}\text { FO system } \\
\text { configuration }\end{array}$} & \multirow{3}{*}{$\begin{array}{l}\text { Membrane } \\
\text { (arrangement) }\end{array}$} & \multicolumn{5}{|c|}{ Removal efficiency (\%) } & \multirow[t]{3}{*}{ Ref } \\
\hline & & \multicolumn{2}{|c|}{ Organic matter } & \multirow{2}{*}{$\begin{array}{l}\text { Phosphorus } \\
\text { TP }\end{array}$} & \multicolumn{2}{|l|}{ Nitrogen } & \\
\hline & & TOC & COD & & $\mathrm{NH}_{4}{ }^{+}-\mathrm{N}$ & TN & \\
\hline \multirow{6}{*}{ Ae-OMBR } & CTA (cross-flow) & $98 \%$ & - & - & $99 \%$ & - & [54] \\
\hline & TFC (cross-flow) & $96 \%$ & - & - & $99 \%$ & - & [54] \\
\hline & $\begin{array}{l}\text { CTA (submerged } \\
\text { plate-and-frame) }\end{array}$ & - & $>99 \%$ & $>99 \%$ & - & $>82 \%$ & [47] \\
\hline & $\begin{array}{l}\text { CTA (submerged } \\
\text { plate-and-frame) }\end{array}$ & $98 \%$ & - & $>99 \% \mathrm{PO}_{4}^{3-}$ & $80-90 \%$ & - & [49] \\
\hline & $\begin{array}{l}\text { CTA (submerged } \\
\text { plate-and-frame) }\end{array}$ & $98 \%$ & - & - & $98 \%$ & - & [55] \\
\hline & $\begin{array}{l}\text { CTA (submerged } \\
\text { plate-and-frame) }\end{array}$ & $>98 \%$ & - & - & $>98 \%$ & - & [24] \\
\hline \multirow{3}{*}{ An-OMBR } & $\begin{array}{l}\text { CTA (submerged } \\
\text { plate-and-frame) }\end{array}$ & - & $>95 \%$ & $>99 \%$ & FO only Ammonia $=70-80 \%$ & - & [28] \\
\hline & $\begin{array}{l}\text { CTA (submerged } \\
\text { plate-and-frame) }\end{array}$ & - & $96.7 \%$ & $99 \%$ & $60 \%$ & - & [26] \\
\hline & $\begin{array}{l}\text { CTA (submerged } \\
\text { plate-and-frame) }\end{array}$ & $92.9 \%$ & & - & - & - & [29] \\
\hline \multirow{2}{*}{$\begin{array}{l}\text { Wastewater } \\
\text { pre- } \\
\text { concentration }\end{array}$} & $\begin{array}{l}\text { CTA (submerged } \\
\text { plate-and-frame) }\end{array}$ & - & $99 \%$ & $99 \% \mathrm{PO}_{4}{ }^{3-}$ & $\begin{array}{l}\text { Ammonia }= \\
67-68 \%\end{array}$ & $56-59 \%$ & {$[56]$} \\
\hline & $\begin{array}{l}\text { CTA (pilot-scale } \\
\text { spiral wound) }\end{array}$ & - & $99.8 \%$ & $99.7 \%$ & $48.1 \%$ & $67.8 \%$ & [40] \\
\hline
\end{tabular}


1 In all FO system configurations discussed above, a high removal efficiency of a broad range 2 of contaminants can be achieved, since FO membranes are highly effective at retaining organic compounds, colloidal particles, and microbes in the feed solution (Table 1).

4 Similarly, FO membranes have consistently demonstrated near complete rejection of 5 phosphorus for two reasons. Electrostatic repulsion occurs between negatively charged 6 phosphate ions and the negative surface charge of the FO membrane, deterring phosphate 7 transport through the membrane. Another important rejection mechanism for phosphorus is 8 size exclusion, as phosphate has a large hydrated radius, it is rejected by a sieving effect [57].

9 The superior rejection capability of FO membranes for organic matter and phosphorus has far reaching implications for wastewater treatment and resource recovery. To highlight this point, conventional An-MBRs (i.e. which utilise MF or UF membranes) cannot achieve sufficient phosphorus removal and have a significantly lower organic matter removal efficiency compared to An-OMBRs [28]. Thus, the integration of FO with anaerobic treatment in the form of An-OMBR can significantly improve the overall system treatment capacity and viability for wastewater treatment.

The removal of nitrogen by FO-based systems is highly variable and depends on the actual structure of nitrogen bearing compounds in the solution and the biological treatment process [58]. FO membranes alone have an incomplete rejection of neutral ammonia (i.e. <80\%) [28, 56] compared with positively charged ammonium ions [57]. At neutral pH, Ae-OMBRs can provide some nitrogen removal capacity as a result of both biological degradation (i.e. via nitrification/denitrification) and FO membrane rejection (Table 1). On the other hand, AnOMBR and FO-anaerobic systems do not provide any biological nitrogen removal capacity. However, it is noteworthy that nitrogen removal could be achieved via struvite (i.e. magnesium ammonium phosphate) recovery, by deploying a dedicated ammonia recovery process, or by converting ammonia microbiologically into nitrous oxide for enhanced biogas utilisation [59].

The high TrOC removal capability of FO membranes is another notable advantage $[60,61]$. Safe implementation of potable water reuse schemes relies on the ability of treatment processes to remove a wide range of TrOCs including, pharmaceutical residues, steroid hormones, phytoestrogens, UV-blockers, and pesticides [62-64]. In terms of FO configurations for wastewater treatment, the Ae-OMBR is likely to offer the most effective removal of TrOCs due to the combined effect of biodegradation and membrane rejection 
1 [60]. It is noteworthy that the removal of TrOCs by An-OMBRs has scarcely been reported in 2 the literature [65].

\section{$3 \quad 2.3 \quad$ FO membrane-based hybrid systems for water recovery}

4 Additional separation processes must be integrated with FO to recover fresh water and re5 concentrate the draw solution. Key considerations for the draw solute recovery process 6 include the ability to reject the draw solutes, draw solution compatibility with the subsequent

7 biological treatment process, and energy requirements of the overall hybrid system. Hybrid 8 systems that couple FO with pressure driven (e.g. NF and reverse osmosis (RO)) [48, 66], 9 thermally driven (e.g. MD) [67-69], or electrically driven (e.g. electrodialysis (ED)) [70] 10 membrane processes have been reported in the literature (Figure 2). In these hybrid systems, 11 FO pre-treats wastewater and provides a foulant-free solution for draw solute recovery. As a 12 result, FO membrane-based hybrid systems have the potential to produce a higher quality 13 effluent and improved process efficiency compared with treating raw wastewater directly 14 with the above mentioned high retention membrane processes [35]. FO membrane-based 15 hybrid systems are often termed as a double-barrier defence for a wide range of 16 contaminants. However, as discussed in the next section, some contaminants can accumulate 17 in the draw solution, presenting a limitation for the practical application of these hybrid systems.

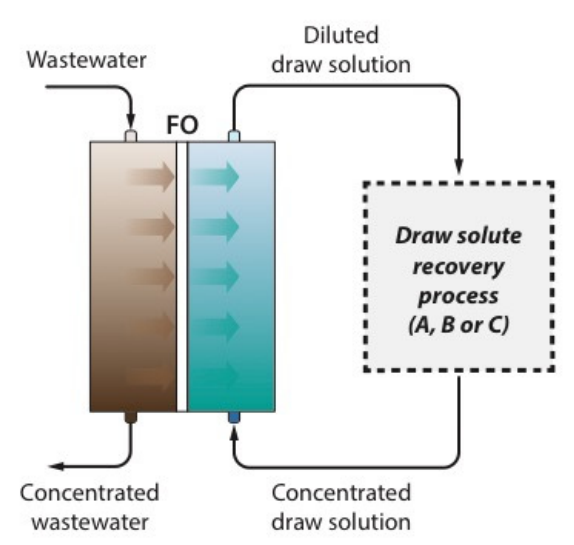

(A)

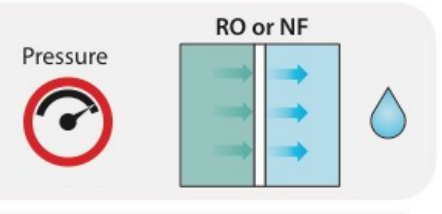

(B)

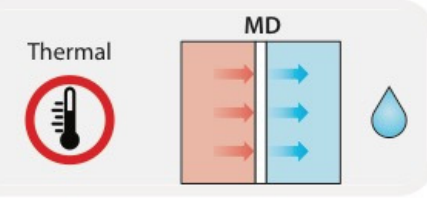

(C)

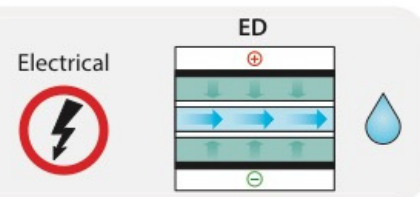

20 Figure 2: Schematic of FO membrane-based hybrid systems utilising: (A) pressure driven $\mathrm{RO}$ or $\mathrm{NF},(\mathrm{B})$ thermally driven $\mathrm{MD}$, and (C) electrically driven ED. 
2 A major limitation for the practical application of FO membrane-based hybrid systems is the 3 potential accumulation of contaminants in the draw solution. FO membranes are not completely impermeable to all dissolved solutes. Thus, contaminants that pass through the FO membrane but are retained by the draw solute recovery process inevitably accumulate in the draw solution of the closed-loop system. Previous studies have observed the accumulation of small organic compounds, ammonium, and phosphate using FO-RO [48] and FO-MD [71] hybrid systems. Accumulation of TrOCs has also been observed, with the type of TrOC depending on the rejection capability difference between the FO and draw solute recovery processes $[71,72]$.

Contaminant accumulation is an issue for the practical application of FO hybrid systems as the product water quality can be hampered and may even lead to membrane fouling in the draw solute recovery process [32, 73]. Luo et al. [48] presented evidence that the accumulation of contaminants in the draw solution of an Ae-OMBR-RO system caused an increased RO permeate concentration of organic matter and ammonium, hence, negatively affecting product water quality. Similar results were reported by D'Haese et al. [72] when they modelled TrOC accumulation in an FO-RO system. They observed TrOC build-up to a value in excess of the feed concentration and led to a contaminated product water [72]. The risk of membrane fouling in the draw solute recovery process caused by contaminant accumulation in the draw solution has also been demonstrated. The permeability of the RO membrane in an OMBR-RO system was shown to gradually decline, suggesting that some small organic molecules can accumulate and act as foulants on the RO membrane [48]. The risk of fouling is also applicable to other draw solute recovery processes after long-term operation, unless mitigation strategies are adopted.

To safegard the production of high quality product water and to reduce the risk of membrane fouling in FO membrane-based hybrid systems, additional treatment processes can be integrated to mitigate contaminant accumulation in the draw solution. The type of treatment process generally depends on the contaminant of concern. In wastewater applications, granular activated carbon (GAC) adsorption and ultraviolet (UV) oxidation have both proved to be effective processes, targeting the mitigation of organic matter and TrOCs [71]. On the other hand, ion exchange has been applied for the removal of accumulated boron in the draw 
1 solution of a seawater desalination process [74]. For wastewater specific applications, further research is required to address a number of practical considerations when mitigating contaminant accumulation in the draw solution. It is noted that draw solution selection can greatly impact the applicability of the applied mitigation strategy. For example, GAC and UV are not compatible when organic-based draw solutions are adopted as the draw solute can interfere with the adsorption process or be degraded by UV radiation, respectively $[38,75]$.

7 Further research is necessary to assess the extent and impact of contaminant accumulation over long-term operation in wastewater applications using FO. Ongoing research progress in the fabrication of FO membranes can improve the rejection of target contaminants and supress their accumulation in the draw solution [76]. Promising results have been achieved through the application of novel side-stream processes to remove contaminants from the draw solution in systems that utilise RO, NF, or MD for draw solute recovery. When ED is used for draw solute recovery, post-treatment methods may be necessary since ED has a relatively low removal capacity for organic compounds [70]. In addition, FO operating parameters can also be optimised to minimise the forward diffusion of contaminants into the draw solution.

\subsubsection{Energy consideration for FO membrane-based hybrid systems}

17 Energy considerations for membrane-based hybrid systems are of paramount importance as the draw solute recovery process dictates the energy consumption of the entire hybrid system [77]. In fact, the FO process itself only requires minimal energy for water transport through the membrane as the draw solution provides the osmotic driving force [31]. FO based hybrid systems can utilise mechanical (i.e. pressure), thermal, or electrical energy to power the draw solute recovery process (Figure 2). Although the energy demand for draw solution regeneration either by $\mathrm{RO}$ or $\mathrm{MD}$ is high [35], it is noteworthy that membrane fouling associated with FO wastewater treatment is highly reversible compared with direct RO [23] or MD filtration [71]. By comparison, during conventional wastewater treatment, intensive pre-treatment is required (i.e. activated sludge treatment and MF) prior to RO for potable water production. In other words, the costs associated with these conventional wastewater treatment processes could be replaced by the FO process.

The most promising avenue for FO membrane-based hybrid treatment systems to provide low energy treatment of wastewater arguably involves applications whereby low-cost heat can be utilised for draw solute recovery. MD is a thermally driven membrane process that has 
1 significant potential, since alternative low-cost or waste thermal energy can be applied to 2 power the draw solute recovery process. It is noteworthy that in all thermally driven 3 processes, the energy efficiency is inversely proportional to temperature (thermal quality) 4 [78]. Thus, the abundance of cheap or free low-grade heat is an important factor. In areas of 5 high solar radiation, solar thermal can be used as the primary energy source. Alternatively, 6 low-grade waste heat could be captured from nearby industrial processes. Lastly, the heat co7 generated from the production of biogas from wastewater organic matter presents a practical 8 approach to supply such thermally driven separation processes.

9 In terms of energy consumption, very few comprehensive comparisons of draw solute 10 recovery processes have been reported in the literature. Life cycle analyses of FO-RO hybrid 11 system primarily focus only on seawater desalination applications. The results were 12 inconclusive and show that at the current stage of FO development, FO-RO processes may 13 have comparable costs [79] or a higher energy use and environmental impact [80] compared 14 with current technology for seawater desalination and water reuse. It is also noted that there 15 has not been any life cycle analysis of FO-based hybrid system specifically for wastewater 16 treatment applications. Further studies are crucial to practically evaluate the energy outlook of FO processes related to wastewater treatment and resource recovery applications.

Another potential opportunity to improve the energy favourability of FO systems involves the case where the diluted draw solution has a direct use, therefore no draw solute recovery process is required. For example, the use of fertilizers as a draw solution to extract clean water for irrigation from compromised sources has been recently demonstrated. The product is a diluted fertiliser solution that can potentially be directly applied for fertigation purposes $[30,81,82]$. In other words, water is recovered in a directly usable form. There is a similar argument for the use of seawater RO brine as the draw solution. Researchers have proposed that diluting the brine by treating wastewater with FO, and subsequently extracting water by seawater RO desalination can provide a sustainable approach to dual issues (i.e. wastewater management and fresh water availability) [83]. In some cases, it has been reported that the required energy for the combined osmotic dilution and water recovery by $\mathrm{RO}$ is more than a single RO process [35]. The suitability of osmotic dilution is highly dependent on local factors, however the low energy consumption of osmotic dilution is a major advantage. 


\section{$1 \quad$ 2.3.3 Other limitations of FO-based hybrid systems}

2 Further to contaminant accumulation in and energy considerations, there are a number of 3 inherent limitations of FO-based hybrid systems. During the process the loss of draw solute 4 (i.e. reverse solute flux) negatively impacts process efficiency by lowering the osmotic 5 driving force [84], increasing operating costs as solute must be periodically supplemented 6 [85], and elevates salinity accumulation in the feed solution [86]. Another limitation is the 7 low water flux of the FO process [87]. Unless significant improvements in membrane 8 materials and draw solution efficiency are made, the capital costs associated with the required 9 FO membrane area to compensate the low flux are extensive.

\section{3. Resource recovery using FO}

11 Extending the established efforts of wastewater treatment, FO has been recognised as a 12 highly suitable technological building block to facilitate nutrient and energy recovery from 13 wastewater. Numerous recent studies have demonstrated the capability of FO-based 14 processes to improve the recovery of energy and nutrients from various wastewaters (Table 15 2). Some of these FO-based processes are able to recover resources whilst simultaneously 16 providing wastewater treatment when coupled with a draw solute recovery process. Despite 17 these promising demonstrations of simultaneous wastewater treatment and resource recovery 18 by FO-based processes, a number of key technical challenges require further development. 19 Further research is needed to optimise the integration of FO with anaerobic processes for 20 biogas production, to overcome issues of salinity accumulation and membrane fouling. Also, 21 it is necessary to focus efforts to develop nutrient recovery using FO to address the key issues 22 of product purity and membrane fouling/scaling during long-term operation. 
1 Table 2: Summary of FO-based resource recovery processes.

\begin{tabular}{|c|c|c|c|c|c|c|}
\hline Feed solution & FO-based process & Recovered resource & $\begin{array}{l}\text { Draw } \\
\text { solution }\end{array}$ & $\begin{array}{l}\text { Draw solute } \\
\text { recovery process }\end{array}$ & Performance & Ref. \\
\hline \multirow{3}{*}{$\begin{array}{l}\text { Synthetic } \\
\text { wastewater }\end{array}$} & An-OMBR & Biogas & $\mathrm{NaCl}$ & $\begin{array}{l}\text { Manual re- } \\
\text { concentration }\end{array}$ & Methane yield $=0.21 \mathrm{~L} \mathrm{CH}_{4} / \mathrm{g} \mathrm{COD}$ & [26] \\
\hline & An-OMBR & Biogas & $\mathrm{NaCl}$ & $\begin{array}{l}\text { Manual re- } \\
\text { concentration }\end{array}$ & Methane yield $=0.3 \mathrm{~L} \mathrm{CH}_{4} / \mathrm{g} \mathrm{COD}$ & {$[28]$} \\
\hline & An-OMBR & Biogas & $\begin{array}{l}\mathrm{NaCl} \text { and } \\
\mathrm{Na}_{2} \mathrm{SO}_{4}\end{array}$ & $\begin{array}{l}\text { Manual re- } \\
\text { concentration }\end{array}$ & $\begin{array}{l}\mathrm{NaCl} \text { An-OMBR had a higher biogas methane } \\
\text { composition than } \mathrm{Na}_{2} \mathrm{SO}_{4} \mathrm{An}-\mathrm{OMBR}\end{array}$ & [29] \\
\hline \multirow{3}{*}{$\begin{array}{l}\text { Activated } \\
\text { sludge }\end{array}$} & Ae-OMBR & Calcium phosphate & $\begin{array}{l}\mathrm{MgCl}_{2} \text { and } \\
\mathrm{NaCl}\end{array}$ & $\begin{array}{l}\text { Manual re- } \\
\text { concentration }\end{array}$ & Phosphorus content $>11 \%$ & [49] \\
\hline & MF-Ae-OMBR & Calcium phosphate & $\begin{array}{l}\text { Seawater } \\
\text { brine }\end{array}$ & Osmotic dilution & $\begin{array}{l}\text { MF extracted dissolved nutrients. } \\
\text { Phosphorus content }=11-13 \%\end{array}$ & {$[88]$} \\
\hline & MF-Ae- OMBR-RO & $\begin{array}{l}\text { Calcium or magnesium } \\
\text { phosphate } \\
\text { Fresh water }\end{array}$ & $\mathrm{NaCl}$ & RO & Precipitate $=15-20 \%$ phosphorus & [48] \\
\hline $\begin{array}{l}\text { Secondary } \\
\text { treated } \\
\text { effluent }\end{array}$ & FO pre-treatment & $\begin{array}{l}\text { Nutrient concentrate (i.e. } \\
\text { ammonia and phosphate) }\end{array}$ & $\begin{array}{l}\text { Synthetic } \\
\text { seawater }\end{array}$ & Osmotic dilution & $\begin{array}{l}\text { Ammonia removal }=66.7 \% \\
\text { Phosphate removal }=92.1\end{array}$ & {$[57]$} \\
\hline \multirow{3}{*}{$\begin{array}{l}\text { Digested } \\
\text { sludge } \\
\text { centrate }\end{array}$} & FO-RO & $\begin{array}{l}\text { Nutrient concentrate (i.e. } \\
\text { ammonia and phosphate) } \\
\text { Fresh water }\end{array}$ & $\mathrm{NaCl}$ & RO & \multirow{3}{*}{$\begin{array}{l}\text { Ammonia removal }=82.9-92.1 \% \\
\text { Phosphate removal }=99.6-99.9 \% \\
\text { Optimum water recovery }=70 \% \\
\text { Ammonium removal }>90 \% \\
\text { Phosphate removal }>97 \% \\
\text { Bidirectional diffusion of } \mathrm{Mg}^{2+} \text { and protons } \\
\text { improved struvite recovery. } \\
\text { Phosphate removal }>98 \% \\
\text { Bidirectional diffusion of protons improved } \\
\text { calcium phosphate recovery. }\end{array}$} & [89] \\
\hline & FO-MD & $\begin{array}{l}\text { Struvite } \\
\left(\mathrm{MgNH}_{4} \mathrm{PO}_{4} \cdot 6 \mathrm{H}_{2} \mathrm{O}\right) \\
\text { Fresh water }\end{array}$ & $\mathrm{MgCl}_{2}$ & MD & & [90] \\
\hline & FO pre-treatment & Calcium phosphate & Seawater & Osmotic dilution & & [91] \\
\hline Urine & FO pre-treatment & $\begin{array}{l}\text { Nutrient concentrate (i.e. } \\
\text { ammonium, phosphate, } \\
\text { and potassium) }\end{array}$ & $\begin{array}{l}\text { Synthetic } \\
\text { seawater } \\
\text { and brine }\end{array}$ & Osmotic dilution & $\begin{array}{l}\text { Ammonium removal }=50-80 \% \\
\text { Phosphate removal }>90 \% \\
\text { Potassium removal }>90 \%\end{array}$ & {$[58]$} \\
\hline
\end{tabular}




\section{$13.1 \quad$ Integrating $\mathrm{FO}$ with anaerobic treatment for biogas production}

2 Integrating the FO process with anaerobic treatment is a promising avenue to produce biogas and recover nutrients from wastewater. Demonstrations of FO-based biogas producing systems have focused almost exclusively on An-OMBRs, where the FO membrane is submerged within the anaerobic bioreactor (Table 2). Recent research has reported the potential of An-OMBRs as methane yields between 0.2-0.3 $\mathrm{L} \mathrm{CH}_{4} / \mathrm{g} \mathrm{COD}$ were achieved in lab-scale studies $[26,28]$. Compared to conventional anaerobic digesters the inclusion of the FO membrane can provide a number of important advantages. The treatment performance of AnOMBRs surpasses conventional anaerobic systems in terms of organic matter and nutrient removal $[10,30]$. FO membrane separation also allows the system to operate at a high organic loading rate by decoupling the hydraulic retention time and the solid retention time, hence, lowering the process footprint [92]. Lastly, potable water production is enabled by adopting an appropriate draw solute recovery process for the draw solution.

An alternative approach that could essentially achieve the same objective of An-OMBRs involves directly processing primarily treated wastewater by FO and then feeding the concentrate to an anaerobic treatment system. As a key advantage of this configuration (Figure 1C), the FO membrane is in contact only with wastewater, which is more dilute than sludge. Sun, et al. [93] reported that fouling reversibility was higher in a direct FO system compared to an OMBR, attributed to differences in the solutions microbiological behaviour [44]. Similarly, membrane degradation may be less severe in direct FO configurations, as prolonged exposure to activated sludge in OMBRs has shown significant performance degradation to both cellulose triacetate (CTA) and thin film composite (TFC) FO membranes [94]. Furthermore, the volumetric loading of the anaerobic treatment system could be drastically reduced, owing to the pre-concentration of wastewater by the FO membrane. Preliminary studies have demonstrated that FO can pre-concentrate COD in dilute wastewater up to approximately eightfold, corresponding to a tenfold volume reduction [38]. Enriching the COD concentration of wastewater has the potential to increase the energy recovery per unit volume of digestate and to minimise heating energy requirement [52].

The primary purpose of considering anaerobic treatment for wastewater treatment is to recover the chemical energy contained in wastewater through biogas conversion. In the proposed FO-based process (Figure 3), biogas produced from the anaerobic treatment process has significant potential to supply the energy requirements of the system. In this case, MD 
1 presents a favourable opportunity for draw solute regeneration, as the driving force of MD is 2 temperature. A combined heat and power engine can convert biogas into heat for the MD 3 system. Furthermore, electricity can be utilised onsite or fed back into the grid. According to 4 an energy audit of the Prague wastewater treatment plant, under an optimal condition, 70$580 \%$ energy self-sufficiency could be achieved by fully utilising the embedded chemical 6 energy in wastewater for biogas production [95]. Thus, energy self-sufficiency is possible 7 with further improvement in engineering efficiency. Lastly, anaerobic treatment partially 8 mineralises organic nitrogen and phosphorus to their soluble forms (i.e. ammonium and 9 phosphate). This action increases the chemical availability of nutrients for subsequent recovery. Despite these benefits, the major technical challenges that limit the feasibility of

11 integrated forward osmosis and anaerobic treatment systems are salinity accumulation and 12 membrane fouling.

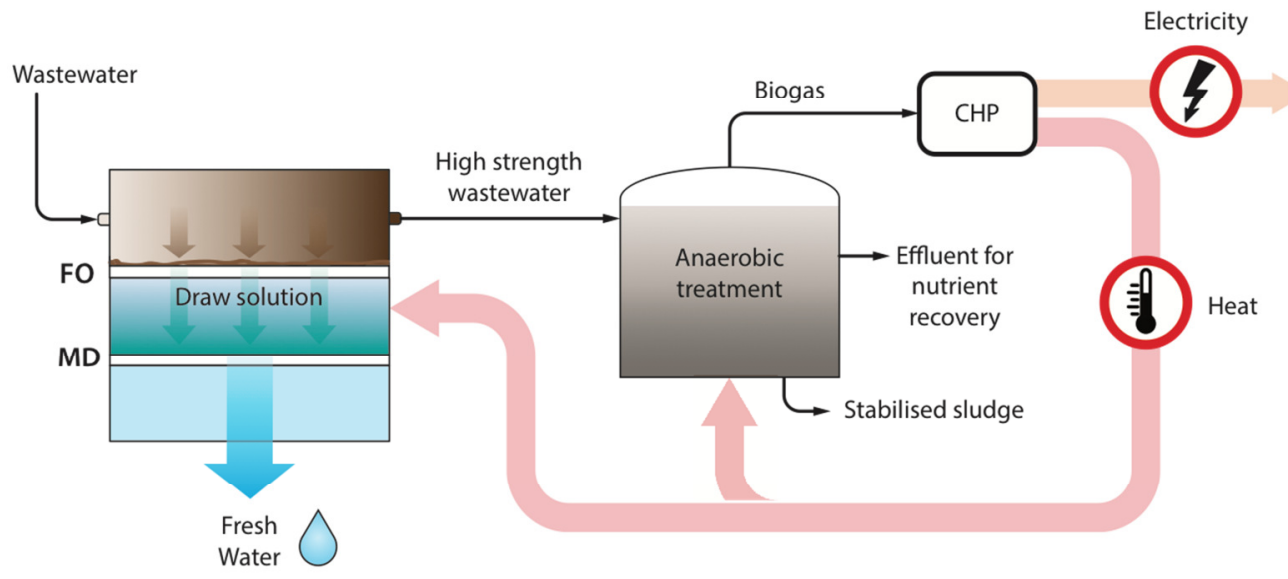

Figure 3: Schematic illustration of an FO pre-concentration process for energy recovery via anaerobic treatment.

\subsubsection{Salinity accumulation}

17 Salinity accumulation is a prevalent issue for the integration of high retention membrane 18 processes with biological treatment [21]. For FO, this issue is further exacerbated by the 19 reverse diffusion of solutes from the draw to the feed solution (i.e. reverse draw solute flux).

20 The accumulation of salt in the feed solution inevitably increases its osmotic pressure and can negatively impact water flux. More importantly, salinity accumulation is a major hindrance when integrating FO with anaerobic treatment since methanogenic activity can be inhibited at

23 high inorganic salt concentrations, leading to severely reduced biogas production rates [96]. It 
1 is noteworthy to mention that methane solubility decreases as salinity increases [97]. This is 2 beneficial in terms of reducing methane loss via permeate. The extent of salinity 3 accumulation and the impact on water flux and anaerobic treatment is strongly affected by the selected draw solution and the FO operating conditions (i.e. concentration factor). The relative contribution of each salinity accumulation mechanism can be predicted based on the operating conditions and draw solute properties [86, 98]. For this application whereby organic loading rates should be increased, the FO concentration factor must be maximised.

8 Yet, the concentration factor is proportional to the rate of salinity build-up and therefore a trade-off exists between the effects of salinity accumulation and process efficiency. Thus, a variety of strategies have been proposed to alleviate salinity accumulation in FO-based systems.

The draw solution significantly influences both the rate of reverse draw solute flux and the type of solutes that accumulate in the feed solution $[84,99]$. Feasibility studies have shown that the use of sodium chloride as the draw solution in An-OMBRs inevitably leads to severe salinity accumulation that detrimentally affects water flux and system efficiency [26, 28]. Furthermore, the accumulation of both sodium chloride and sodium sulphate draw solutes significantly impacted growth of methanogens in An-OMBRs [29]. One approach to mitigate this problem is to utilise alternative draw solutes (Figure 4A). A draw solution selection criterion has been developed specifically for FO processes that integrate anaerobic treatment, to assess the risk of methanogenic inhibition as a result of reverse draw solute flux $[27,30]$. Overall, ionic organic draw solutes such as sodium acetate (NaOAc) and ethylenediaminetetraacetic acid (EDTA) based salts hold the biggest promise. The reverse solute flux of NaOAc and EDTA-2Na are $70 \%$ and $86 \%$ lower than sodium chloride, which reduces the rate of salinity accumulation and draw solute replenishment [27, 100]. In addition, the biodegradation of these solutes can enhance biogas production [27]. To date, organic ionic draw solutes have been demonstrated in a lab-scale Ae-OMBR and have shown excellent mitigation of salinity build-up in the reactors $[67,75]$. However, further research is required to assess the application of organic ionic draw solutes within anaerobic FO systems.

The high cost of ionic organic draw solutes remains an important barrier for the practical 30 implementation of these FO draw solutions. For this reason, a number of recent demonstrations of FO integrated anaerobic systems have generally adopted cost effective sodium chloride or seawater as the draw solution and relied on non-optimal operating 
1 conditions, such as excessive sludge wastage or periodic supernatant discharge in order to 2 avoid the effects of salinity build-up on the process [26, 28]. Although these studies present 3 the feasibility of biogas production (i.e. 0.2-0.3 $\mathrm{L} \mathrm{CH}_{4} / \mathrm{g} \mathrm{COD}$ ) via the An-OMBR process, 4 conditions are unrealistic and are not a feasible long-term solution to salinity accumulation. A 5 proof of concept which can potentially lead to a full-scale sustainable option for salinity 6 mitigation involves the integration of an MF membrane within an Ae-OMBR [88, 101]. The

7 MF membrane acts as a bleeding stream since dissolved solutes can easily pass through the 8 MF membrane (Figure 4B). This integrated system manages to sustain the FO process, whilst 9 at the same time producing MF quality effluent for reuse applications requiring lower water 10 qualities. Similar benefits may also be realised if MF is integrated with An-OMBR, however 11 this approach would result in the partial loss of organic substances.
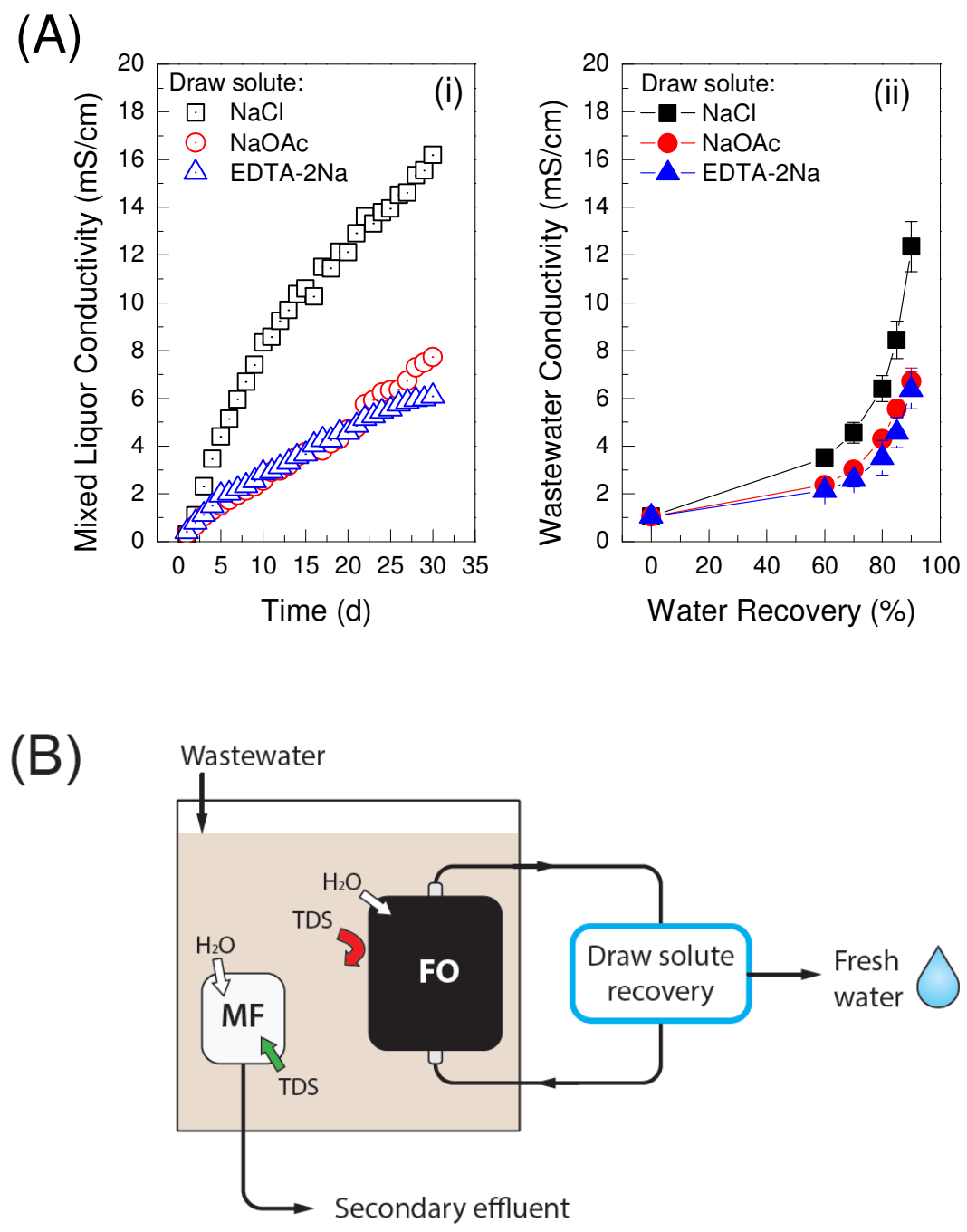
1 Figure 4: Mitigation of salinity accumulation by (A) alternative draw solutions for (i) AeOMBR [75] and (ii) wastewater pre-concentration [38], and (B) MF withdrawal of total

4 Another promising approach involves acclimatising the anaerobic microbial community to 5 saline environments. In anaerobic systems, microorganisms are able to tolerate high salt 6 conditions if acclimated to the conditions [102, 103]. Indeed, the anaerobic treatment of high 7 saline industrial wastewater is feasible with adequate biomass adaption or by using 8 halotolerant organisms [104]. Further research on identifying and implementing certain

9 halotolerant bacteria in an anaerobic system would be significantly beneficial to developing 10 FO-based anaerobic systems. The presence of halotolerant organisms would allow the FO 11 system to operate at a higher concentration factor. Furthermore, when draw solutions with a 12 low reverse solute flux are applied, the negative impacts associated with salinity 13 accumulation on biogas production would be circumvented. Overall, a greater focus is 14 required to assess and advance the practicality of FO-based systems that integrate anaerobic treatment for biogas production. A combination of the previously mentioned strategies in a pilot-scale system would significantly contribute to assessing their long-term effectiveness, and is imperative to improving our understanding of FO-based anaerobic systems.

\subsubsection{Membrane fouling}

Although FO membrane fouling is readily reversible, fouling remains a pertinent issue for FO-based processes applied to complex solutions such as wastewater and mixed liquor [44, $73,105]$. During the filtration process, the accumulation of foulants on the membrane surface forms a cake layer and hinders the efficiency of the process by two prominent mechanisms. The cake layer builds hydraulic resistance and also creates the cake-enhanced concentration polarisation effect that lowers the osmotic driving force. Both these mechanisms adversely impact membrane performance, by decreasing water flux and membrane life-span [35, 44]. Various approaches have been demonstrated to manage membrane fouling. These include physical and chemical cleaning methods, as well as modification of membranes to be fouling resistant.

A key benefit of the FO process when applied for wastewater pre-concentration is the highly reversible nature of membrane fouling compared to other pressure driven membrane processes. Therefore, membrane fouling control can often be accomplished by hydraulic 
1 means, whereby hydrodynamic shear forces are introduced to prevent the accumulation of 2 foulants near the membrane surface [106, 107]. This method is not possible when using 3 pressure driven membrane processes for direct wastewater treatment since fouling cannot be 4 removed without chemical cleaning. Hydrodynamic strategies including periodic rinsing at 5 high cross flow velocities, inclusion of spacers, and air sparging via biogas recycling, which 6 have proved effective in wastewater treatment applications [26, 106, 108]. Despite these

7 results, the intensity of the fouling control strategy inevitably leads to heightened energy 8 consumption. Therefore, a significant focus should be placed on evaluating and optimising 9 the energy consumption of proposed fouling mitigation strategies. It is also necessary to develop a membrane cleaning protocol specific for intense wastewater pre-concentration

11 applications by FO membranes.

\subsubsection{Issues arising from the anaerobic treatment of FO pre-concentrated wastewater}

13 In addition to the key challenges of salinity accumulation and membrane fouling, a range of 14 other issues may arise as a result of the anaerobic treatment of FO pre-concentrated 15 wastewater. Inorganic salt inhibition and ammonia toxicity may plague the efficiency of the anaerobic treatment process, regardless of mitigation strategies. In this case, the co-digestion of readily available organic substrates (i.e. food waste or industrial by-products) could significantly improve the digester efficiency [109, 110]. Furthermore, phosphorus may precipitate in the anaerobic reactor due to the enriched content of phosphorus, calcium, and magnesium in the pre-concentrated wastewater [26]. This may lead to complications for phosphorus recovery, as the availability of phosphorus in the liquid phase would be limited. However, this scenario could be easily avoided by acidifying the pre-concentrate. The conventional MF An-MBR is an ideal candidate for biogas production from the preconcentrated wastewater. In addition, the ammonia and phosphorus rich supernatant (i.e. anaerobic digestion effluent) can be withdrawn via the MF membrane for subsequent recovery.

Studies to date have focused almost exclusively on the integration of FO and anaerobic treatment to form An-OMBRs [26, 28, 29] or to filter anaerobic effluent [111-113]. Therefore, there is a significant gap in current knowledge regarding the anaerobic treatment of FO pre-concentrated wastewater. 
2 The rejection of nutrients by FO membranes results in high quality product water, and can 3 also facilitate the removal and recovery of nutrients from wastewater. Phosphorus in 4 particular has significant environmental value and consistently presents a high rejection by 5 FO membranes from a range of different feed solutions and operation conditions (Table 1). In 6 recent years, there has been a significant growth in nutrient recovery research using FO-based 7 processes [7]. Phosphorus recovery from a number of diverse source waters, including waste activated sludge [48, 49, 88], secondary treated effluent [57], digested sludge centrate [89-

9 91], and urine [58] has been demonstrated in the literature. Several FO-based configurations 10 have been applied including Ae-OMBR and direct FO filtration. Overall, FO is utilised to 11 firstly concentrate nutrients, and then conventional nutrient recovery techniques are applied to chemically precipitate either struvite, or calcium phosphates (Table 2).

13 FO has several features that are ideal for nutrient recovery from wastewater. Firstly, FO membranes can effectively retain phosphorus, thus enriching its concentration and providing favourable conditions for phosphorus recovery. As an example, struvite recovery requires the addition of magnesium salt and ammonium to exceed the stoichiometric ratio for struvite precipitation. Thus, the phosphorus rich solution provided by the FO process improves precipitation kinetics and lowers the chemical demand (i.e. magnesium salts and caustic). Secondly, the reverse solute flux (which is usually seen as problematic in FO) can be utilised for nutrient recovery applications. Xie et al. [90] strategically utilised $\mathrm{MgCl}_{2}$ as a draw solution to enrich the magnesium content of the feed solution via the reverse magnesium flux mechanism. Lastly, the bidirectional diffusion of solutes in the FO process enables the feed solution $\mathrm{pH}$ to naturally increase. Several researchers have observed this bidirectional transport phenomenon. In particular, Xie et al. [90] and Ansari et al. [91] have demonstrated the direct benefit of the bidirectional transport of $\mathrm{Mg}^{2+} / \mathrm{Ca}^{2+}$ and proton $\left(\mathrm{H}^{+}\right)$for struvite and calcium phosphate precipitation, respectively.

There are a number of configuration options for FO-based systems for nutrient recovery. AeOMBRs treating dilute wastewater have demonstrated excellent potential for nutrient enrichment within the mixed liquor or by supernatant withdrawal $[49,88,114]$ (Figure 5A).

30 Also, direct pre-concentration processes applied to anaerobic digestion effluent has presented 31 promising results as this system could be easily integrated with current wastewater treatment infrastructure $[90,91]$. In terms of nutrient recovery efficiency, the direct pre-concentration 
1 of anaerobic effluent (i.e. digested sludge centrate) is possibly the most viable approach as 2 there is minimal loss of nutrients caused by biomass uptake, as is the case in Ae-OMBRs. In 3 aerobic processes, nutrients are consumed or converted by activated sludge, therefore, a 4 lower theoretical amount of phosphorus is available for recovery. Conversely, anaerobic 5 treatment biologically releases nutrients, transforming them into more chemically available 6 forms for precipitation (Figure 5B).

(A)

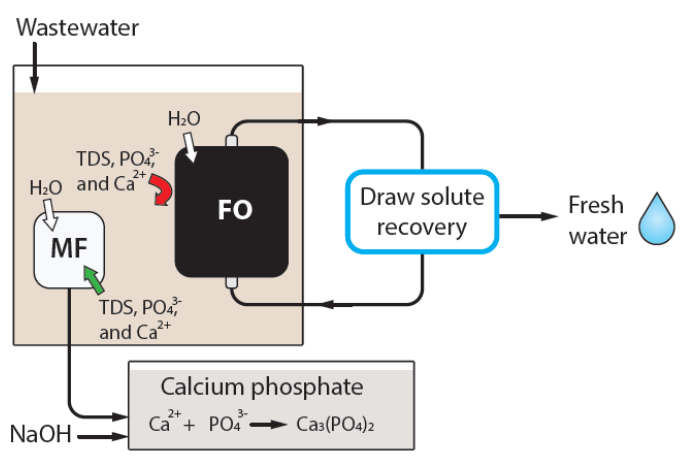

(B)

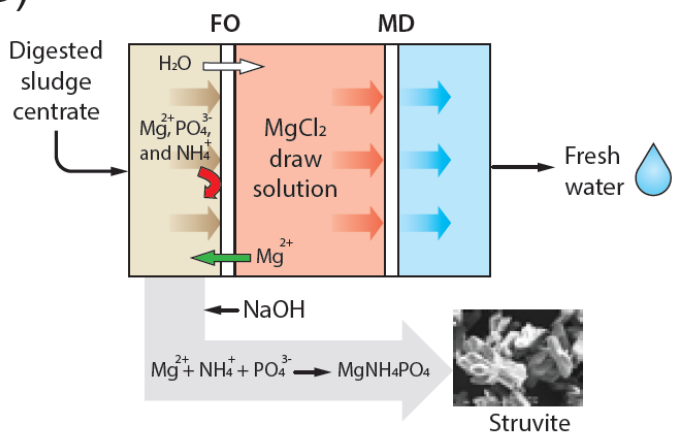

7

Investigations into FO performance when treating nutrient rich solutions are increasing [111-

Figure 5: Phosphorus recovery using (A) MF withdrawal from Ae-OMBR mixed liquor (adapted from Qiu et al. [88]) and (B) FO-MD of anaerobically digested sludge centrate (adapted from Xie et al. [90]).

113], however there are still several key aspects to be addressed. These include membrane fouling and scaling, precipitate purification, and issues related to the market development for bio-fertilizers produced from wastewater.

Membrane scaling could be a prominent barrier for FO application to nutrient recovery; however, this issue has not been investigated. It is important to consider the possibility of membrane scaling during resource recovery as it dramatically affects process performance and chemical cleaning is often required, resulting in a decreased membrane life-span. The super saturation of phosphate minerals close to the membranes surface may lead to the precipitation of salts onto the membrane surface. Research to date has not identified any significant problems associated with membrane scaling during nutrient recovery applications. This is likely due to the short term nature of the proof of concept studies in the current literature. Pilot-scale evaluation and modelling are required to assess the risk of membrane scaling for nutrient recovering FO processes and formulation of chemical cleaning protocols. 
1 In addition to membrane scaling, the presence of calcium and phosphate in the FO feed 2 solution can lead to cake layer formation [115]. Nevertheless, membrane flushing has been 3 reported to be an effective strategy to remove cake formation [90, 91].

4 One key advantage for nutrient recovery is the potential profit obtained from the sale of the 5 bio-fertilizers produced. Nevertheless, a market for fertilisers sourced from wastewater is 6 currently not well-defined. The product value largely depends on the purity of the obtained

7 product. At this stage, product purity has not been a significant area of research for the 8 previously mentioned FO-based nutrient recovery systems. For example, for calcium 9 phosphate recovery, the competition of calcium and magnesium for phosphate and the presence of organic matters can drastically degrade product quality [88, 91]. There is significant potential for FO-based processes to be further integrated with established resource recovery techniques. These may include the introduction of seed crystallisation [116] or by further purification of FO pre-concentrated nutrient solutions by technologies such as ED [7].

\section{Integrated FO-based wastewater treatment and resource recovery process}

Based on current FO research and development, an integrated FO-based wastewater treatment and resource recovery process is proposed and compared with current wastewater treatment practices (Figure 6). Current wastewater treatment (Figure 6A) is highly energy intensive, with aeration and pressurised membrane systems being significant energy consumers. The process also focusses strictly on water reclamation and does not effectively integrate energy and nutrient recovery practices. Although sludge is often anaerobically treated, a large portion of the chemical energy in wastewater is dissipated by the initial aerobic biological process [18].

Unlike current wastewater treatment practice, the proposed FO-based process (Figure 6B) focuses on the separation of water and non-water components to enable more efficient resource recovery. In this process, primarily treated effluent is firstly filtered by the FO process coupled with MD to produce high quality effluent for reuse. Organic ionic draw solutes are employed to minimise reverse draw solute flux, and to lower the risk of methane inhibition during anaerobic digestion. The FO pre-concentrate is fed to an anaerobic digester to produce biogas. A combined heat and power system converts biogas to useful heat for operating MD, and electricity for treatment operations. Furthermore, nutrient rich anaerobic effluent is processed by an FO-MD system to further harvest valuable nutrients for 
1 subsequent recovery. Struvite recovery can be achieved using $\mathrm{MgCl}$ as the draw solution 2 [90], whilst calcium phosphate can be recovered using seawater [90]. This MD system would 3 also produce high quality effluent for reuse, which is a significant benefit, as anaerobic 4 effluent is commonly returned to the headworks in conventional treatment plants. For these 5 reasons, FO can potentially serve as a game changer in municipal wastewater treatment.

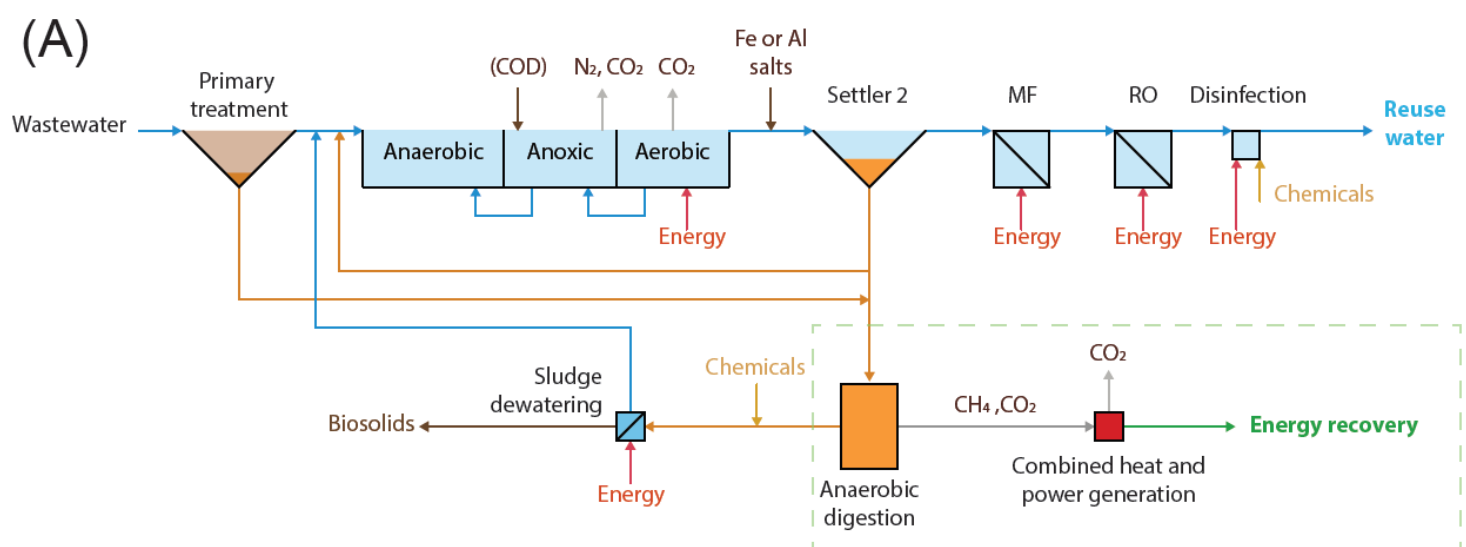

(B)

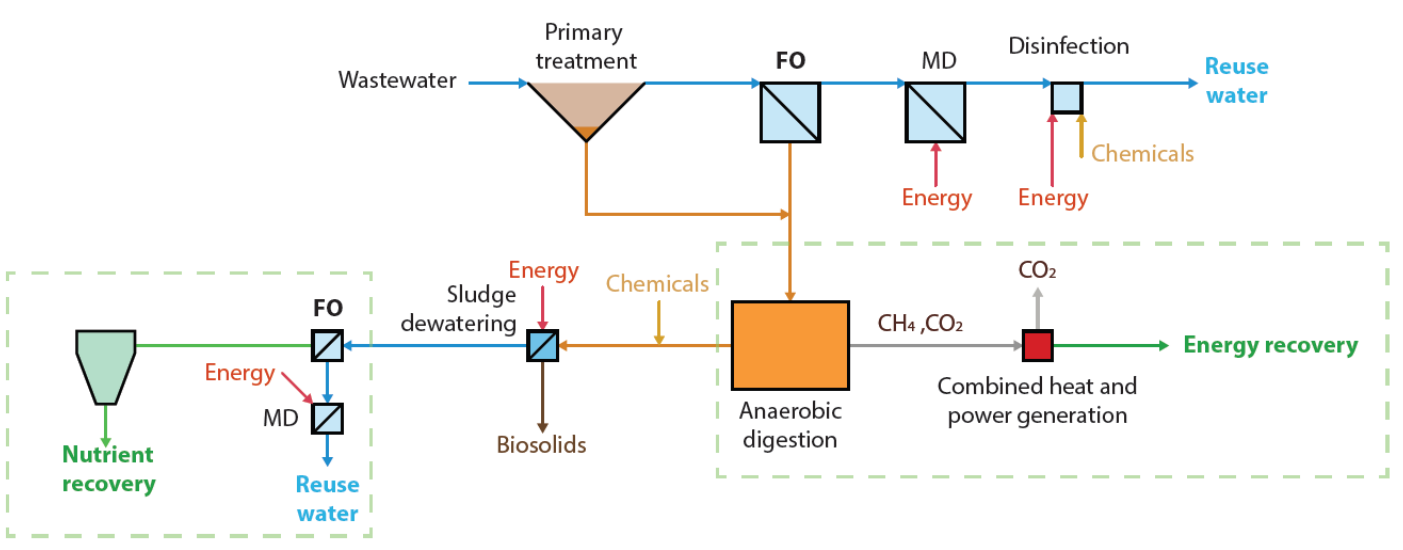

$9 \quad$ Figure 6: Comparison of current and FO-based wastewater treatment technologies. (A)

10 Current processes consume significant energy, dissipate wastewater organic matter, and do 11 not effectively manage nutrients (adapted from Verstraete et al. [16]). (B) The proposed FO-

12 based treatment process achieves simultaneous wastewater treatment and resource recovery, utilising produced energy within its operations and recovers nutrients.

\section{5. Outlook}

15 FO-based processes have a proven capability and offer a unique opportunity to achieve 16 simultaneous wastewater treatment and resource recovery. Yet, FO technology is still in the 
1 early stage of development and therefore the realisation of full-scale implementation will continue to evolve as the field becomes more mature. Two important considerations for this concept include the applicability of FO-based systems to a decentralised or centralised level and economic barriers that strongly affect the acceptance of the technology.

5 Issues regarding the scale-up of FO based processes involve the inherently low water flux of 6 the FO process. Low water flux corresponds to a large footprint which substantially increases 7 capital and operational costs. Considering the direct filtration of raw wastewater by FO, with 8 the current state of FO membranes, environmental and economic benefits may only be 9 realised for decentralised applications. This is due to the significantly large volumetric loading of centralised wastewater treatment systems in urban areas. Furthermore, there is an increasing drive to house treatment facilities onsite or nearby to the water reuse locations (i.e. farming areas or industrial areas) [117]. This concept of sewer mining strategically avoids the energy needed to convey reuse water from a centralised wastewater treatment plant, however quality control would be an added issue to be addressed. Further investigations to assess the feasibility of FO scale-up must be conducted in terms of both technical and economic viability. In the future, improvements of FO membrane materials, module design, draw solutions, and draw solute recovery processes may provide practical opportunities for the scale-up of FO systems at a centralised level.

Regarding nutrient recovery using FO-based technology, important advantages are likely to be realised sooner as the process can be integrated with current wastewater treatment infrastructure (i.e. treating anaerobically digested sludge centrate). Furthermore, nutrient recovery presents a practical business case for struvite blockage prevention, phosphorus effluent discharge compliance, and fertilizer production potential [118]. In fact, struvite recovery has been demonstrated at several full-scale wastewater treatment plants in North America [119]. We envisage that FO can greatly improve the process efficiency and therefore break-down some of the economic barriers that prevent nutrient recovery being an established practice [120].

Resource recovery from municipal wastewater presents a promising outlook for a number of contemporary environmental challenges. However, several economic barriers exist and restrict the acceptance and implementation of such practices. The environmental value of water, energy, and nutrient resources cannot be readily captured by current economic 
1 analysis. This is illustrated by the availability of low cost electricity, natural gas, and 2 mineable phosphorus that strongly resist investment appeal. Furthermore, the lack of a well3 defined market for saleable bio-fertilizers remains may influence the acceptance of nutrient recovery technologies. Nonetheless, resource recovery from wastewater represents a renewable source of water, energy, and nutrients. Particularly when considering how population growth and urbanisation will continue to stress non-renewable resource reserves in the future. The introduction of government incentives may provide a profound milestone in 8 implementing resource recovery practices. Further investigations into the economic 9 feasibility of technologies that enable resource recovery from wastewater should be a high 10 priority.

\section{6. Conclusion}

12 The FO process is a favourable avenue to advance a membrane-based platform to achieve 13 simultaneous wastewater treatment and resource recovery. FO membranes can be applied to a 14 complex and high fouling solution and retain a wide range of contaminants. FO membrane15 based hybrid systems that combine FO with a draw solute recovery process (i.e. MD) 16 effectively enable fresh water recovery from wastewater. Extending this effort, energy and nutrient recovery from wastewater can be initiated through the strategic integration of FO with anaerobic biological treatment. FO membranes can successfully pre-concentrate wastewater and improve the organic loading rate of anaerobic treatment systems for biogas production. Similarly, the FO process can harvest the valuable nutrients within anaerobic effluent, and significantly benefit the efficiency of established phosphorus recovery techniques.

Despite the potential of FO to emerge as an important membrane technology in the future, several major technical challenges still remain. These include contaminant accumulation in the draw solution, salinity accumulation, membrane fouling, and anaerobic system integration. A number of innovative approaches can be utilised to resolve these challenges as highlighted in this review. Further development of the practical aspects of this concept via pilot-scale demonstrations is recommended. One major milestone in the development of FO technology for this application involves the successful demonstration of integrated FO and anaerobic treatment systems. Furthermore, energy considerations for the proposed process must also be clearly dictated through techno-economic assessments that address the likely advantages of the process compared with current technologies. Issues associated with the 
1 scale-up of FO-based processes at a decentralised or centralised level must also be addressed.

2 Development of FO membrane materials and anaerobic microbial selection techniques are

3 expected to strongly benefit research progress towards FO-based technology for simultaneous

4 wastewater treatment and resource recovery.

\section{Acknowledgements}

6 This research was supported under the Australian Research Council's Discovery Project

7 funding scheme (project DP140103864). Scholarship support to Ashley Ansari by the

8 University of Wollongong is gratefully acknowledged.

\section{References}

10 [1] M.A. Shannon, P.W. Bohn, M. Elimelech, J.G. Georgiadis, B.J. Marinas, A.M. Mayes, 11 Science and technology for water purification in the coming decades, Nature, 452 (2008) $12 \quad 301-310$.

13 [2] J.J. Bogardi, D. Dudgeon, R. Lawford, E. Flinkerbusch, A. Meyn, C. Pahl-Wostl, K. 14 Vielhauer, C. Vorosmarty, Water security for a planet under pressure: interconnected 15 challenges of a changing world call for sustainable solutions, Curr Opin Env Sust, 4 (2012) $16 \quad 35-43$.

17 [3] W.W. Li, H.Q. Yu, B.E. Rittmann, Chemistry: Reuse water pollutants, Nature, 528 (2015) $18 \quad 29-31$.

19 [4] R.H.E.M. Koppelaar, H.P. Weikard, Assessing phosphate rock depletion and phosphorus 20 recycling options, Global Environ. Chang., 23 (2013) 1454-1466.

21 [5] J. Elser, E. Bennett, Phosphorus cycle: A broken biogeochemical cycle, Nature, 478 22 (2011) 29-31.

23 [6] G.K. Morse, S.W. Brett, J.A. Guy, J.N. Lester, Review: Phosphorus removal and recovery 24 technologies, Sci. Total Environ., 212 (1998) 69-81.

25 [7] M. Xie, H.K. Shon, S.R. Gray, M. Elimelech, Membrane-based processes for wastewater 26 nutrient recovery: Technology, challenges, and future direction, Water Res., 89 (2016) 21027221.

[8] W.W. Mo, Q. Zhang, Energy-nutrients-water nexus: Integrated resource recovery in 29 municipal wastewater treatment plants, J. Environ. Manage., 127 (2013) 255-267.

30 [9] Y. Lorenzo-Toja, I. Vázquez-Rowe, M.J. Amores, M. Termes-Rifé, D. Marín-Navarro, 31 M.T. Moreira, G. Feijoo, Benchmarking wastewater treatment plants under an eco-efficiency 32 perspective, Sci. Total Environ., 566-567 (2016) 468-479.

33 [10] A.L. Smith, L.B. Stadler, N.G. Love, S.J. Skerlos, L. Raskin, Perspectives on anaerobic 34 membrane bioreactor treatment of domestic wastewater: A critical review, Bioresour. 35 Technol., 122 (2012) 149-159. 
[11] D.L. Sills, V.L. Wade, T.D. DiStefano, Comparative Life Cycle and Technoeconomic Assessment for Energy Recovery from Dilute Wastewater, Environ. Eng. Sci., 33 (2016) 861-872.

[12] J. Frijns, J. Hofman, M. Nederlof, The potential of (waste)water as energy carrier, Energ.

40 Convers. Manage., 65 (2013) 357-363.

[13] D.J. Batstone, T. Hülsen, C.M. Mehta, J. Keller, Platforms for energy and nutrient recovery from domestic wastewater: A review, Chemosphere, 140 (2015) 2-11.

[14] H. Gao, Y.D. Scherson, G.F. Wells, Towards energy neutral wastewater treatment: methodology and state of the art, Environ. Sci. Process Impacts, 16 (2014) 1223-1246.

[15] M.D. Seib, K.J. Berg, D.H. Zitomer, Low energy anaerobic membrane bioreactor for municipal wastewater treatment, J. Membr. Sci., 514 (2016) 450-457.

[16] W. Verstraete, S.E. Vlaeminck, ZeroWasteWater: short-cycling of wastewater resources for sustainable cities of the future, Int J Sust Dev World, 18 (2011) 253-264.

[17] P.L. McCarty, J. Bae, J. Kim, Domestic wastewater treatment as a net energy producercan this be achieved?, Environ Sci Technol, 45 (2011) 7100-7106.

[18] J. Wan, J. Gu, Q. Zhao, Y. Liu, COD capture: a feasible option towards energy selfsufficient domestic wastewater treatment, Sci. Rep., 6 (2016) 25054.

[19] F.A. Meerburg, N. Boon, T. Van Winckel, J.A.R. Vercamer, I. Nopens, S.E. Vlaeminck, Toward energy-neutral wastewater treatment: A high-rate contact stabilization process to maximally recover sewage organics, Bioresour. Technol., 179 (2015) 373-381.

[20] I. Shizas, D. Bagley, Experimental Determination of Energy Content of Unknown Organics in Municipal Wastewater Streams, J. Energ. Eng., 130 (2004) 45-53.

[21] W. Luo, F.I. Hai, W.E. Price, W. Guo, H.H. Ngo, K. Yamamoto, L.D. Nghiem, High retention membrane bioreactors: Challenges and opportunities, Bioresour. Technol., 167 (2014) 539-546.

[22] M. Xie, J. Lee, L.D. Nghiem, M. Elimelech, Role of pressure in organic fouling in forward osmosis and reverse osmosis, J. Membr. Sci., 493 (2015) 748-754.

[23] S. Lee, C. Boo, M. Elimelech, S. Hong, Comparison of fouling behavior in forward osmosis (FO) and reverse osmosis (RO), J. Membr. Sci., 365 (2010) 34-39. bioreactor: A low fouling alternative to MBR processes, Desalination, 239 (2009) 10-21. 
[26] L. Chen, Y. Gu, C. Cao, J. Zhang, J.-W. Ng, C. Tang, Performance of a submerged anaerobic membrane bioreactor with forward osmosis membrane for low-strength wastewater treatment, Water Res., 50 (2014) 114-123.

[27] A.J. Ansari, F.I. Hai, W. Guo, H.H. Ngo, W.E. Price, L.D. Nghiem, Selection of forward osmosis draw solutes for subsequent integration with anaerobic treatment to facilitate resource recovery from wastewater, Bioresour. Technol., 191 (2015) 30-36.

[28] Y. Gu, L. Chen, J.-W. Ng, C. Lee, V.W.C. Chang, C.Y. Tang, Development of anaerobic osmotic membrane bioreactor for low-strength wastewater treatment at mesophilic condition, J. Membr. Sci., 490 (2015) 197-208.

[29] M.K.Y. Tang, H.Y. Ng, Impacts of different draw solutions on a novel anaerobic forward osmosis membrane bioreactor (AnFOMBR), Wat. Sci. Tech., 69 (2014) 2036-2042.

[30] Y. Kim, L. Chekli, W.-G. Shim, S. Phuntsho, S. Li, N. Ghaffour, T. Leiknes, H.K. Shon, Selection of suitable fertilizer draw solute for a novel fertilizer-drawn forward osmosisanaerobic membrane bioreactor hybrid system, Bioresour. Technol., 210 (2016) 26-34.

[31] T.Y. Cath, A.E. Childress, M. Elimelech, Forward osmosis: Principles, applications, and recent developments, J. Membr. Sci., 281 (2006) 70-87.

[32] L. Chekli, S. Phuntsho, J.E. Kim, J. Kim, J.Y. Choi, J.-S. Choi, S. Kim, J.H. Kim, S. Hong, J. Sohn, H.K. Shon, A comprehensive review of hybrid forward osmosis systems: Performance, applications and future prospects, J. Membr. Sci., 497 (2016) 430-449.

[33] K. Lutchmiah, A.R.D. Verliefde, K. Roest, L.C. Rietveld, E.R. Cornelissen, Forward osmosis for application in wastewater treatment: A review, Water Res., 58 (2014) 179-197.

[34] R.W. Holloway, A. Achilli, T.Y. Cath, The osmotic membrane bioreactor: A critical review, Environ. Sci.: Water Res. Technol., 1 (2015) 581-605.

[35] D.L. Shaffer, J.R. Werber, H. Jaramillo, S. Lin, M. Elimelech, Forward osmosis: Where are we now?, Desalination, 356 (2015) 271-284.

[36] A. Subramani, J.G. Jacangelo, Emerging desalination technologies for water treatment: A critical review, Water Res., 75 (2015) 164-187.

[37] K. Lutchmiah, L. Lauber, K. Roest, D.J.H. Harmsen, J.W. Post, L.C. Rietveld, J.B. van Lier, E.R. Cornelissen, Zwitterions as alternative draw solutions in forward osmosis for application in wastewater reclamation, J. Membr. Sci., 460 (2014) 82-90.

[38] A.J. Ansari, F.I. Hai, W. Guo, H.H. Ngo, W.E. Price, L.D. Nghiem, Factors governing the pre-concentration of wastewater using forward osmosis for subsequent resource recovery, Sci. Total Environ., 566-567 (2016) 559-566.

[39] X. Zhang, Z. Ning, D.K. Wang, J.C. Diniz da Costa, Processing municipal wastewaters by forward osmosis using CTA membrane, J. Membr. Sci., 468 (2014) 269-275. 
[40] Z. Wang, J. Zheng, J. Tang, X. Wang, Z. Wu, A pilot-scale forward osmosis membrane

106 system for concentrating low-strength municipal wastewater: performance and implications,

107 Sci. Rep., 6 (2016) 21653.

108 [41] B.D. Coday, P. Xu, E.G. Beaudry, J. Herron, K. Lampi, N.T. Hancock, T.Y. Cath, The 109 sweet spot of forward osmosis: Treatment of produced water, drilling wastewater, and other 110 complex and difficult liquid streams, Desalination, 333 (2014) 23-35.

111 [42] R. Valladares Linares, Z. Li, S. Sarp, S.S. Bucs, G. Amy, J.S. Vrouwenvelder, Forward 112 osmosis niches in seawater desalination and wastewater reuse, Water Res., 66 (2014) 122113139.

114 [43] Q. Yang, J. Lei, D.D. Sun, D. Chen, Forward Osmosis Membranes for Water 115 Reclamation, Sep. Purif. Rev., 45 (2016) 93-107.

116 [44] Q. She, R. Wang, A.G. Fane, C.Y. Tang, Membrane fouling in osmotically driven 117 membrane processes: A review, J. Membr. Sci., 499 (2016) 201-233.

118 [45] X. Wang, V.W.C. Chang, C.Y. Tang, Osmotic membrane bioreactor (OMBR) 119 technology for wastewater treatment and reclamation: Advances, challenges, and prospects 120 for the future, J. Membr. Sci., 504 (2016) 113-132.

121 [46] E.A. Bell, R.W. Holloway, T.Y. Cath, Evaluation of forward osmosis membrane performance and fouling during long-term osmotic membrane bioreactor study, J. Membr. Sci., 517 (2016) 1-13.

[47] R.W. Holloway, J. Regnery, L.D. Nghiem, T.Y. Cath, Removal of Trace Organic Chemicals and Performance of a Novel Hybrid Ultrafiltration-Osmotic Membrane Bioreactor, Environ Sci Technol, 48 (2014) 10859-10868.

127 [48] W. Luo, F.I. Hai, W.E. Price, W. Guo, H.H. Ngo, K. Yamamoto, L.D. Nghiem, 128 Phosphorus and water recovery by a novel osmotic membrane bioreactor-reverse osmosis 129 system, Bioresour. Technol., 200 (2016) 297-304.

130 [49] G. Qiu, Y.-P. Ting, Direct phosphorus recovery from municipal wastewater via osmotic 131 membrane bioreactor (OMBR) for wastewater treatment, Bioresour. Technol., 170 (2014) 132 221-229.

133 [50] W.C.L. Lay, Y. Liu, A.G. Fane, Impacts of salinity on the performance of high retention 134 membrane bioreactors for water reclamation: A review, Water Res., 44 (2010) 21-40.

135 [51] S.H. Park, B. Park, H.K. Shon, S. Kim, Modeling full-scale osmotic membrane 136 bioreactor systems with high sludge retention and low salt concentration factor for 137 wastewater reclamation, Bioresour. Technol., 190 (2015) 508-515.

138 [52] C.-H. Wei, M. Harb, G. Amy, P.-Y. Hong, T. Leiknes, Sustainable organic loading rate 139 and energy recovery potential of mesophilic anaerobic membrane bioreactor for municipal 140 wastewater treatment, Bioresour. Technol., 166 (2014) 326-334.

141 [53] S. Zou, H. Yuan, A. Childress, Z. He, Energy Consumption by Recirculation: A Missing 142 Parameter When Evaluating Forward Osmosis, Environ Sci Technol, 50 (2016) 6827-6829. 
[54] X. Wang, Y. Zhao, B. Yuan, Z. Wang, X. Li, Y. Ren, Comparison of biofouling

144 mechanisms between cellulose triacetate (CTA) and thin-film composite (TFC) polyamide forward osmosis membranes in osmotic membrane bioreactors, Bioresour. Technol., 202 (2016) 50-58.

147 [55] G. Qiu, Y.-P. Ting, Osmotic membrane bioreactor for wastewater treatment and the effect of salt accumulation on system performance and microbial community dynamics, Bioresour. Technol., 150 (2013) 287-297.

150 [56] R. Valladares Linares, Z. Li, M. Abu-Ghdaib, C.-H. Wei, G. Amy, J.S. Vrouwenvelder, 151 Water harvesting from municipal wastewater via osmotic gradient: An evaluation of process 152 performance, J. Membr. Sci., 447 (2013) 50-56.

153 [57] W. Xue, T. Tobino, F. Nakajima, K. Yamamoto, Seawater-driven forward osmosis for enriching nitrogen and phosphorous in treated municipal wastewater: Effect of membrane properties and feed solution chemistry, Water Res., 69 (2015) 120-130.

156 [58] J. Zhang, Q. She, V.W.C. Chang, C.Y. Tang, R.D. Webster, Mining Nutrients (N, K, P) 157 from Urban Source-Separated Urine by Forward Osmosis Dewatering, Environ Sci Technol, 15848 (2014) 3386-3394.

159 [59] Y.D. Scherson, S.-G. Woo, C.S. Criddle, Production of Nitrous Oxide From Anaerobic 160 Digester Centrate and Its Use as a Co-oxidant of Biogas to Enhance Energy Recovery, 161 Environ Sci Technol, 48 (2014) 5612-5619.

162 [60] B.D. Coday, B.G.M. Yaffe, P. Xu, T.Y. Cath, Rejection of Trace Organic Compounds 163 by Forward Osmosis Membranes: A Literature Review, Environ Sci Technol, 48 (2014) $164 \quad 3612-3624$.

165 [61] A.A. Alturki, J.A. McDonald, S.J. Khan, W.E. Price, L.D. Nghiem, M. Elimelech, 166 Removal of trace organic contaminants by the forward osmosis process, Sep. Purif. Technol., 167103 (2013) 258-266.

168 [62] K.C. Wijekoon, F.I. Hai, J. Kang, W.E. Price, W. Guo, H.H. Ngo, L.D. Nghiem, The 169 fate of pharmaceuticals, steroid hormones, phytoestrogens, UV-filters and pesticides during 170 MBR treatment, Bioresour. Technol., 144 (2013) 247-254.

171 [63] Y. Luo, W. Guo, H.H. Ngo, L.D. Nghiem, F.I. Hai, J. Zhang, S. Liang, X.C. Wang, A 172 review on the occurrence of micropollutants in the aquatic environment and their fate and 173 removal during wastewater treatment, Sci. Total Environ., 473-474 (2014) 619-641.

174 [64] H. Siegrist, A. Joss, Review on the fate of organic micropollutants in wastewater 175 treatment and water reuse with membranes, Wat. Sci. Tech., 66 (2012) 1369-1376.

176 [65] X. Song, J. McDonald, W.E. Price, S.J. Khan, F.I. Hai, H.H. Ngo, W. Guo, L.D. 177 Nghiem, Effects of salinity build-up on the performance of an anaerobic membrane 178 bioreactor regarding basic water quality parameters and removal of trace organic 179 contaminants, Bioresour. Technol., 216 (2016) 399-405. 

draw solutions for minimizing reverse salt flux to improve forward osmosis desalination, Sci. Total Environ., 538 (2015) 129-136.

[67] N.C. Nguyen, H.T. Nguyen, S.-S. Chen, H.H. Ngo, W. Guo, W.H. Chan, S.S. Ray, C.W. Li, H.-T. Hsu, A novel osmosis membrane bioreactor-membrane distillation hybrid system for wastewater treatment and reuse, Bioresour. Technol., 209 (2016) 8-15. wastewater via forward osmosis-membrane distillation (FO-MD), Water Res., 52 (2014) 112-

[69] N.C. Nguyen, H.T. Nguyen, S.-T. Ho, S.-S. Chen, H.H. Ngo, W. Guo, S.S. Ray, H.-T. Hsu, Exploring high charge of phosphate as new draw solute in a forward osmosismembrane distillation hybrid system for concentrating high-nutrient sludge, Sci. Total Environ., 557-558 (2016) 44-50.

[70] Y. Zhang, L. Pinoy, B. Meesschaert, B. Van Der Bruggen, A natural driven membrane process for brackish and wastewater treatment: Photovoltaic powered ED and FO hybrid system, Environ Sci Technol, 47 (2013) 10548-10555.

[71] M. Xie, L.D. Nghiem, W.E. Price, M. Elimelech, A Forward Osmosis-Membrane Distillation Hybrid Process for Direct Sewer Mining: System Performance and Limitations, Environ Sci Technol, 47 (2013) 13486-13493.

[72] A. D'Haese, P. Le-Clech, S. Van Nevel, K. Verbeken, E.R. Cornelissen, S.J. Khan, A.R.D. Verliefde, Trace organic solutes in closed-loop forward osmosis applications: Influence of membrane fouling and modeling of solute build-up, Water Res., 47 (2013) 52325244.

203 [73] S. Zhao, L. Zou, C.Y. Tang, D. Mulcahy, Recent developments in forward osmosis: Opportunities and challenges, J. Membr. Sci., 396 (2012) 1-21.

[74] D.L. Shaffer, N.Y. Yip, J. Gilron, M. Elimelech, Seawater desalination for agriculture by integrated forward and reverse osmosis: Improved product water quality for potentially less energy, J. Membr. Sci., 415-416 (2012) 1-8.

[75] W. Luo, F.I. Hai, W.E. Price, M. Elimelech, L.D. Nghiem, Evaluating ionic organic draw solutes in osmotic membrane bioreactors for water reuse, J. Membr. Sci., 514 (2016) 636-645.

[76] A.G. Fane, R. Wang, M.X. Hu, Synthetic membranes for water purification: Status and future, Angew. Chem. Int. Ed., 54 (2015) 3368-3386.

[77] M. Khayet, J.A. Sanmartino, M. Essalhi, M.C. García-Payo, N. Hilal, Modeling and optimization of a solar forward osmosis pilot plant by response surface methodology, Sol. Energy, 137 (2016) 290-302. (2015). 
220 J.S. Vrouwenvelder, Life cycle cost of a hybrid forward osmosis - low pressure reverse osmosis system for seawater desalination and wastewater recovery, Water Res., 88 (2016) 225-234.

[80] R.W. Holloway, L. Miller-Robbie, M. Patel, J.R. Stokes, J. Munakata-Marr, J. Dadakis, T.Y. Cath, Life-cycle assessment of two potable water reuse technologies: MF/RO/UV-AOP treatment and hybrid osmotic membrane bioreactors, J. Membr. Sci., 507 (2016) 165-178.

[81] M. Xie, M. Zheng, P. Cooper, W.E. Price, L.D. Nghiem, M. Elimelech, Osmotic dilution for sustainable greenwall irrigation by liquid fertilizer: Performance and implications, J. Membr. Sci., 494 (2015) 32-38.

[82] S. Zou, Z. He, Enhancing wastewater reuse by forward osmosis with self-diluted commercial fertilizers as draw solutes, Water Res., 99 (2016) 235-243.

[83] T.Y. Cath, N.T. Hancock, C.D. Lundin, C. Hoppe-Jones, J.E. Drewes, A multi-barrier osmotic dilution process for simultaneous desalination and purification of impaired water, J. Membr. Sci., 362 (2010) 417-426.

[84] S. Zhao, L. Zou, Relating solution physicochemical properties to internal concentration polarization in forward osmosis, J. Membr. Sci., 379 (2011) 459-467.

[85] A. Achilli, T.Y. Cath, A.E. Childress, Selection of inorganic-based draw solutions for forward osmosis applications, J. Membr. Sci., 364 (2010) 233-241.

[86] D. Xiao, C.Y. Tang, J. Zhang, W.C.L. Lay, R. Wang, A.G. Fane, Modeling salt accumulation in osmotic membrane bioreactors: Implications for FO membrane selection and system operation, J. Membr. Sci., 366 (2011) 314-324.

241 [87] W.C.L. Lay, J. Zhang, C. Tang, R. Wang, Y. Liu, A.G. Fane, Factors affecting flux performance of forward osmosis systems, J. Membr. Sci., 394-395 (2012) 151-168.

[88] G. Qiu, Y.-M. Law, S. Das, Y.-P. Ting, Direct and Complete Phosphorus Recovery from Municipal Wastewater Using a Hybrid Microfiltration-Forward Osmosis Membrane Bioreactor Process with Seawater Brine as Draw Solution, Environ Sci Technol, 49 (2015) 6156-6163.

[89] R.W. Holloway, A.E. Childress, K.E. Dennett, T.Y. Cath, Forward osmosis for concentration of anaerobic digester centrate, Water Res., 41 (2007) 4005-4014.

[90] M. Xie, L.D. Nghiem, W.E. Price, M. Elimelech, Toward Resource Recovery from

250 Wastewater: Extraction of Phosphorus from Digested Sludge Using a Hybrid Forward 251 Osmosis-Membrane Distillation Process, Environ. Sci. Technol. Lett., 1 (2014) 191-195.

252 [91] A.J. Ansari, F.I. Hai, W.E. Price, L.D. Nghiem, Phosphorus recovery from digested 253 sludge centrate using seawater-driven forward osmosis, Sep. Purif. Technol., 163 (2016) 1-7. Manage., 182 (2016) 477-485. 

(FO) membrane for municipal wastewater treatment: A comparison between direct FO and OMBR, Water Res., 104 (2016) 330-339.

260 [94] W. Luo, M. Xie, F.I. Hai, W.E. Price, L.D. Nghiem, Biodegradation of cellulose 261 triacetate and polyamide forward osmosis membranes in an activated sludge bioreactor: 262 Observations and implications, J. Membr. Sci., 510 (2016) 284-292.

263

[95] P. Jenicek, J. Bartacek, J. Kutil, J. Zabranska, M. Dohanyos, Potentials and limits of anaerobic digestion of sewage sludge: Energy self-sufficient municipal wastewater treatment plant?, Wat. Sci. Tech., 66 (2012) 1277-1281.

[96] L. Appels, J. Baeyens, J. Degrève, R. Dewil, Principles and potential of the anaerobic digestion of waste-activated sludge, Prog. Energ. Combust., 34 (2008) 755-781.

[97] Z.H. Liu, H. Yin, Z. Dang, Y. Liu, Dissolved methane: A hurdle for anaerobic treatment of municipal wastewater, Environ Sci Technol, 48 (2014) 889-890.

[98] S. Kim, Scale-up of osmotic membrane bioreactors by modeling salt accumulation and draw solution dilution using hollow-fiber membrane characteristics and operation conditions, Bioresour. Technol., 165 (2014) 88-95.

[99] L. Chekli, S. Phuntsho, H.K. Shon, S. Vigneswaran, J. Kandasamy, A. Chanan, A review of draw solutes in forward osmosis process and their use in modern applications, Desalin. Water Treat., 43 (2012) 167-184.

[100] K.S. Bowden, A. Achilli, A.E. Childress, Organic ionic salt draw solutions for osmotic membrane bioreactors, Bioresour. Technol., 122 (2012) 207-216.

[101] W. Luo, F.I. Hai, J. Kang, W.E. Price, L.D. Nghiem, M. Elimelech, The role of forward osmosis and microfiltration in an integrated osmotic-microfiltration membrane bioreactor system, Chemosphere, 136 (2015) 125-132.

[102] T. Panswad, C. Anan, Impact of high chloride wastewater on an anaerobic/anoxic/aerobic process with and without inoculation of chloride acclimated seeds, Water Res., 33 (1999) 1165-1172.

[103] G. Feijoo, M. Soto, R. Méndez, J.M. Lema, Sodium inhibition in the anaerobic digestion process: Antagonism and adaptation phenomena, Enzyme Microb. Technol., 17 (1995) 180-188.

[104] O. Lefebvre, R. Moletta, Treatment of organic pollution in industrial saline wastewater: A literature review, Water Res., 40 (2006) 3671-3682.

[105] B. Mi, M. Elimelech, Chemical and physical aspects of organic fouling of forward osmosis membranes, J. Membr. Sci., 320 (2008) 292-302.

[106] C. Boo, M. Elimelech, S. Hong, Fouling control in a forward osmosis process integrating seawater desalination and wastewater reclamation, J. Membr. Sci., 444 (2013) 148-156. 

reversibility and cleaning without chemical reagents, J. Membr. Sci., 348 (2010) 337-345.

296 [108] R. Valladares Linares, Z. Li, V. Yangali-Quintanilla, Q. Li, G. Amy, Cleaning protocol for a FO membrane fouled in wastewater reuse, Desalin. Water Treat., 51 (2013) 4821-4824.

298

299

300

301

302

303

304

305

306

307

308

309

310

311

312

[109] L. Zhang, T.L.G. Hendrickx, C. Kampman, H. Temmink, G. Zeeman, Co-digestion to support low temperature anaerobic pretreatment of municipal sewage in a UASB-digester, Bioresour. Technol., 148 (2013) 560-566.

[110] L.D. Nghiem, T.T. Nguyen, P. Manassa, S.K. Fitzgerald, M. Dawson, S. Vierboom, Co-digestion of sewage sludge and crude glycerol for on-demand biogas production, Int. Biodeter. Biodegr., 95, Part A (2014) 160-166.

[111] Y. Ding, Y. Tian, Z. Li, F. Liu, H. You, Characterization of organic membrane foulants in a forward osmosis membrane bioreactor treating anaerobic membrane bioreactor effluent, Bioresour. Technol., 167 (2014) 137-143.

[112] Y. Ding, Y. Tian, J. Liu, N. Li, J. Zhang, W. Zuo, Z. Li, Investigation of microbial structure and composition involved in membrane fouling in the forward osmosis membrane bioreactor treating anaerobic bioreactor effluent, Chem. Eng. J., 286 (2016) 198-207.

[113] S. Onoda, Y. Masumori, T. Miyoshi, M. Yasukawa, T. Takahashi, H. Matsuyama, Rejection of nutrients contained in an anaerobic digestion effluent using a forward osmosis membrane, Desalin. Water Treat., 57 (2016) 15748-15758.

[114] R.W. Holloway, A.S. Wait, A. Fernandes da Silva, J. Herron, M.D. Schutter, K. Lampi, T.Y. Cath, Long-term pilot scale investigation of novel hybrid ultrafiltration-osmotic membrane bioreactors, Desalination, 363 (2015) 64-74.

[115] R.Y. Ning, T.L. Troyer, Colloidal fouling of RO membranes following MF/UF in the reclamation of municipal wastewater, Desalination, 208 (2007) 232-237.

[116] Y.h. Song, D. Donnert, U. Berg, P.G. Weidler, R. Nueesch, Seed selections for crystallization of calcium phosphate for phosphorus recovery, J. Environ. Sci., 19 (2007) 591-595.

[117] J.G. Hering, T.D. Waite, R.G. Luthy, J.E. Drewes, D.L. Sedlak, A Changing Framework for Urban Water Systems, Environ Sci Technol, 47 (2013) 10721-10726.

[118] E. Desmidt, K. Ghyselbrecht, Y. Zhang, L. Pinoy, B. Van der Bruggen, W. Verstraete, K. Rabaey, B. Meesschaert, Global Phosphorus Scarcity and Full-Scale P-Recovery Techniques: A Review, Crit. Rev. Env. Sci. Technol., 45 (2014) 336-384.

[119] N. Cullen, R. Baur, P. Schauer, Three years of operation of North America's first nutrient recovery facility, Wat. Sci. Tech., 68 (2013) 763-768.

[120] B.K. Mayer, L.A. Baker, T.H. Boyer, P. Drechsel, M. Gifford, M.A. Hanjra, P. Parameswaran, J. Stoltzfus, P. Westerhoff, B.E. Rittmann, Total Value of Phosphorus Recovery, Environ Sci Technol, 50 (2016) 6606-6620. 